UCID. 18725

\title{
RESULTS AND ANALYSIS OF THE TMX ELECTRON-BEAM \\ INJECTION EXPERTMFNTS
}

P. Poulsen

D. P. Grubb

August 1, 1980

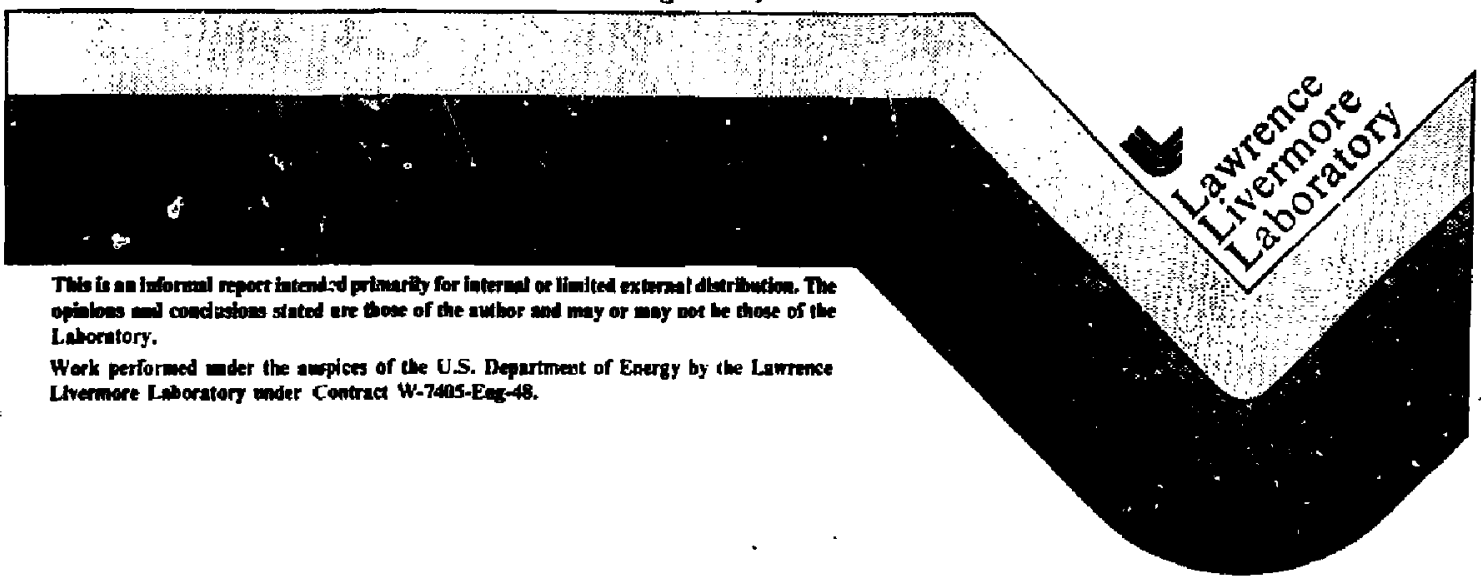

DISTRIBUTIOH OF THIS DOCUMENT IS GHLLHIIEC 


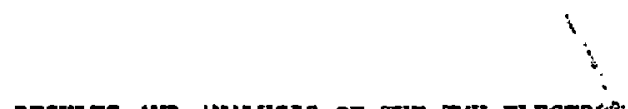

RESULTS AND ANALYSIS OF THE TMX ELECTRY?-BEAY

INJECTION EXPERIMENTS

ABSTRACT

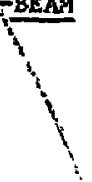

Electron beams (e-beams) were injected into the Tandem Mirror Experiment (TMX) plasma in order to invegtigate the effect on the ion cyclotron, fluctuations of the plasma. The power level of the e-beams was compatable to that of the injected neutral. beans. It was found that injection of the e-beams produced ns significant effect on the ion cyclotron fluctuations, the measured plasma parameters, or the particle and power flow of the plasma. The increase in bulk electron cemperature and the production of mirror-confined electrons found in previous experiments in which e-beams were injected into a mirror-confined plasma were not observed in this experiment. Analysis of the regions and frequencies of wave creation and absorption within tne plasma shows that the plasma density and magnetic field profiles through the plasma strorgly affect the resonances encountered by the waves. The steep axial density frofiles produced by treutral-beam injection in the Mx experiment are not conducive to efficient coupting of the e-beam energy to the plasma. It appears that efficient heating can be achieved if the fundarental electron cyclotron resonance is locrced in a high-density region within the mirror. Plasma density profiles sitisfying this requirement can be produced in neutra1beam-suscained plasmas.

\section{INTRODUCT ICN}

The ion cyclotron fluctuation in the end plugs of the Tandem Mirror Experiment ( $M M$ ) confinement device at Lawrence Livermore National Laboratory (LLNL) is presently stabilized by plasma streaming from the central cell through the plugs. As the level of tile fluctuation increases, the axial confinement in the crutral cell decreases as a consequence of the streamingplasma requirements of the end plugs. 1 Previous experiments at the Massachusetts Institute of Technology (MIT) ${ }^{2}$ and I.LNL ${ }^{3,4}$ had indicated that the injection of electron beams (e-beams) into the plasma was a possible method of reducing the ion cyclotron fluctuations and thus of improving the

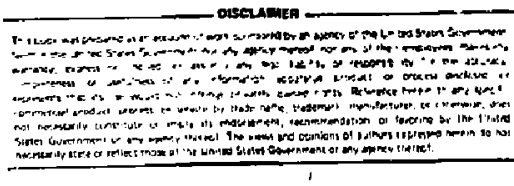


cintral-celt confinement. We therefore decided to invesrigate the injec:ion of e-beams into the TMX plasma.

The experiment showed that injection of the e-beams did not in general affect the fluctuation level and the plasma parametera. However, at low plasma densities in the end flugs $\left(\omega_{p}<\omega_{c}\right.$ at $\left.B_{m i n}\right)$ and low fluctuation levels, instances of $r f$ reduction and electron bulk heating were found.

Analysis of the interaction of an e-beam with the TMX plasma showed that the efficiency and mechaniss by which the energy of the high-frequency ( 25 to $50 \mathrm{GHz}$ ) waves was absorbed by the plasma depended on the axial profiles of density and magnetic field. In particular, the neutral-beam-iriven plasmas employed in the LLNL mirror confinement experiments to date possess steep axial density gradients and high densities $\left(\omega_{p} \geq \omega_{c}\right)$. The configuration of these plasmas does not allow efficient absorption at the fundamental electron cyclotron frequency; it is this Eeature whith distinguishes the inte:-tion of e-beams with the present neutral-beam-driven plasmas from the interaction with streaming-plasma-gun plasmas or self-generated plasmas.

The experiments contuczed with the object of reducing ion cyclotron fiuctuations in mirror-confined plasmas are sumarized in Table 1 and in the following paralzaphs.

In the experiments at MIT and on the 2XIIB device at LLM, the data showed that plasma parameters existed for which injection of an e-beam into the mirror-confined plasma would decrose or eliminate the ion cyclotron instabilities in the plasma. In the MTT experiment, the plasma was injected into the mirror by a Ti-washer streaming-plasma gun. At low neutral densities $\left(\leq 10^{11} \mathrm{~cm}^{-3}\right)$ aild injection durations less thar $0.5 \mathrm{~ms}$, an instability would be observed during the decay of the plasma. If an e-beam were injected simultaneo:sly with the streaming plasma, both having a duration of $0.4 \mathrm{~ms}$, the instability would be surpressed for e-beam powers in excess of $41 \mathrm{kw}$. Injection of the e-beam and the streaming plasma for shorter durations such that the peak plasma density was less than $-5 \times 10^{12} \mathrm{~cm}^{-3}$ did not result in quiescent decay of the plasme. 5

The LLML experiments with the $2 X I I B$ plasma were conducted in two parts. In the first, a single e-beaw, similar to that employed at MIT, was injected into the 2 XIIB plasma. At high lensities and turbulence levels, injection of the e-beam had no measurable effect; at densities less than $6 \times 10^{12} \mathrm{~cm}^{-3}$, during the decay of the plasma, injection of the e-beam would sustain the line 
TABLE 1. Sumary of experiments using e-beam injection to reduce ion cyclotron fluctuations in uirrox-cunfined plasmas.

\begin{tabular}{|c|c|c|c|c|c|}
\hline Experiment & $\begin{array}{l}\text { Effect on } \\
\text { Eluctuation }\end{array}$ & $\begin{array}{l}w_{p}^{w} f_{c}^{w} \\
a t \\
\mathbf{B}_{\min }\end{array}$ & $\begin{array}{l}\text { Hard } \\
(>50 \mathrm{keV}) \\
\times \text { rays }\end{array}$ & $\begin{array}{l}\text { e-beam } \\
\text { power }\end{array}$ & $\begin{array}{l}\text { Bolis } \\
\text { electron } \\
\text { heating }\end{array}$ \\
\hline$\frac{\text { MIT: }}{\text { I gun }}$ & Reducedc & $0 \leq 06$ & Yes & $340 \mathrm{~kW}$ & $\begin{array}{l}\text { Yes; } 10 \text { ev to } \\
20 \mathrm{ev}\end{array}$ \\
\hline $\begin{array}{l}\text { 2XIIB: } \\
1 \text { gun; injec- } \\
\text { tion outside } \\
\text { mirror }\end{array}$ & $\begin{array}{l}\text { (a) Reduced } \\
\text { (b) None }\end{array}$ & $\begin{array}{c}1 \\
2 \text { to } 5\end{array}$ & $\begin{array}{l}\text { No } \\
\text { No }\end{array}$ & 20 to $300 \mathrm{~kW}$ & $\begin{array}{l}\text { Not } \\
\text { measured }\end{array}$ \\
\hline $\begin{array}{l}4 \text { guns; } 2 \\
\text { guns located } \\
\text { outside mirror }\end{array}$ & None & 2 =0 5 & Mo & 0.5 to $2 \mathrm{MW}$ & No \\
\hline $\begin{array}{l}4 \text { guns; } 2 \\
\text { guns located } \\
\text { at mirror } \\
\text { points }\end{array}$ & Reducedd & 2 to 5 & No & 0.5 to $2 \mathrm{MH}$ & $\begin{array}{l}T_{e} \text { (ave) } \\
\text { decreased } \\
\text { from } 68 \mathrm{eV} \\
\text { to } 59 \mathrm{eV}\end{array}$ \\
\hline \multicolumn{6}{|l|}{ TMX: } \\
\hline$\overline{F a n}$ injection & $\begin{array}{l}\text { None (except } \\
\text { as noted in } \\
\text { text) }\end{array}$ & 1 to 2 & Not measured & & $\begin{array}{l}\text { None (bulk } \\
\text { heating in } \\
\text { single plug) }\end{array}$ \\
\hline $\begin{array}{l}\text { Axial injec- } \\
\text { tion outside } \\
\text { mirror points }\end{array}$ & None & 1 to 2 & No & 0.2 to 1 & No \\
\hline $\begin{array}{l}\text { Axial injec- } \\
\text { tion at } \\
\text { mirror points }\end{array}$ & Reduced tht & 1 to 2 & No & $0.5 \mathrm{~mW}$ & $\begin{array}{c}T_{e} \\
\text { decreased }\end{array}$ \\
\hline
\end{tabular}

a Where $\omega_{p}$ is the plasma frequescy and $c$ is the electron cyclotron frequency.

$b$ In the MIT experiment, the plasma was fueled by a streaming-plasma gun.

In all other experiments listed here, the source was perpendicular neutralbear injection.

c Plasma fluctuations were reduced only for certain ranges of e-beam power and injection duration.

d Results obscured hecause e-beam struck material surfaces. 
density of the plasma for the duration of the e-beam pulse, while at the same time eliminating the plasma turbulence.

After finding this corresponden, with the results of the MIr experiments, four e-beams were injected into the $2 \times I I B$ plasma; it was found thit the results obtained were the same as those obtained with the injection of a single e-beam. Placing an electron-beam gun (e-gun) at each mirror point and irjecting the e-beam did affect the plasma at high densities $\left(\sim 3 \times 10^{13} \mathrm{~cm}^{-3}\right)$. The turbulence level, while not eliminated, was reduced significantly, and the line dengity was maintained for the duration of the e-beam pulse. Dianagnetic loops signals did not show an enhancement in son energy confinement time, in contradiction with the expected behavior at reduced turbulence levels. It is probable that the results from this experitunt were affected by the inpact of one e-beam onto the surface of an opposing gun.

As a continuation of these experimenta, two sets of e-beam experiments were conducted on TMX. In the first, e-beams were injected into the TMX plasma from guns placed on the vacuum wall in the end fan of the east plug. At high densities in the end plugs $\left(n \geq 2 \times 10^{13} \mathrm{~cm}^{-3}\right.$ ), injection of the G-beams had no measurable effect on the plast $z$ parameters or the turbulence level. At low density leve1s $\left(\mathrm{n}<10^{13} \mathrm{~cm}^{-3}\right)$ in the end plugs, we found that conditions existed for which the power in the fundamental frequency band and the first two harmonics could be reduced. At the same time, if power appeared at irequencies other than the fundamental and its first two harmonics. The electron temperature did not increase or decrease during the experiments, nor did other plasma parameters vary. Operation of a single end plug, the east, with $n_{0}$ gas feed to the central cell or neutral-beam curzent to the west plug, produced evidence of bull: heating of the plasma electrons when the e-bean was injected into a lawdensity $\left(n<10^{13} \mathrm{~cm}^{-3}\right)$ plasma. The plasma electron temperature increased from approximately $90 \mathrm{eV}$ to $140 \mathrm{eV}$.

In a second set of experiments, we placed an e-gun at each outside mirror point of the $M X X$ machine, and e-beams were injected into the plasma. After an: initial burst of $\mathrm{If}$, the turbulence leval in the machine subsided. However, the electron temperature also tecreesed with a resulting decrease in potential confinement. We found after the experiment that be e-beam from the e-gun in the west plug had struck the surface of the e-gun in the east plug; we speculate that the electron temperature was reduced by inelastic scattering and enhanced heat conduction resulting from the interaction of the plasma 
electrons with the gas and impurities from the surface of the east e-gun. The decrease in electron temperature and plug plasma potential could account for the observed decrease in turbulence level, according to quasi-linear theory. Injection of e-beams into a turbulent, dense $\left(\mathrm{n}>2 \times 10^{13} \mathrm{~cm}^{-3}\right)$, mirrorconfined plasma has thus been shown to be ineffective in suppressing plasma turbulence. The theory of e-beam/plasma interaction shows the conditions for which effective coupling between the e-beam and the plasma occurs. The coupling depends upon the spatial variation and magnitude of the plasma density and the magnetic field. The frequencies of the plasma waves that are generated by the e-beam will in most cases of interest lie between the plasma frequency and the upper hybrid frequency. If the confining magnetic field is of such a magnitude that the fundamental elestron cyclotron resonance corresponding to the excited fiequency is within the confinement region and accessible to the waves, the coupling of the beam energy to the trapped plasma will be effective. If not, the coupling is not effective, and the bean will not strongly perturb the plasma parameters. A comparison between theory and the MIT, 2XIIB, and TMX experiments shows that in the experiments where the e-beams directly affected the plasma pardmeters, the coupling corresponded to absorption of the plasma waves at the electron cyclotron resonance lacated in a high-density region within the magnetic mirror. In the experiments on 2 XIIB and TMX for which the density was high enough that $\omega_{p}^{2} \gg \omega_{c}^{2}$, we found that absorption at the fundamental electron cyclotron resonance is not faured, and that instead the waves are either absorbed at the plasma resonance or they leave the confinement region. Under these conditions, the injected e-beam does not appear to affect the plasma parameiers.

The TMX end-fan injection experimerts are described in Sec. 2, the TMX axial-injection experiments in Sec. 3, and the theory in Sec. 4. The results of the MIT, $2 X I I B$, and TMX experiments are examined and cocpared in Sec. 5. The last section also contains a brief discussion of the manner in which e-beam injection can cemplement or replace electron cyclotron resonant heating (ECRH) in future experiments.

\section{TMX END-FAN INJECTION EXPERIMENTS}

For the first e-beam experiment on TMX, e-guns were mounted on the flange at the east end of TMX. The e-beams were injected along the flux tube into 
the TMX plasma. The guns mapped to $x=4.5$ in the center plasma of the east plug. The arrangement is shown in Fig. 1. The e-gun assembly is shown schematically in Fig. 2 and discussed in Ref. 4.

The magnetic field for the experiments consisted of a magnetic field on each end of a solenoidal field as show in Fig. 3. The mirror firlds were 1.8-T maximum, 0.9-T minimum, and the magnetic field wos $0.2 \mathrm{~T}$ in the solenoidal section.

The experiment, the greater part of which was conducted on Navember 28, 1979, was in two parts. In the first part, the e-beams were injected into the normal tanden mirror plasma configuration. The experiment was conducted over a range of power levels, both of the e-beams and of the neutral beams; the power level of the e-beams ranged from 0.2 to 2 hW; the neutral-beam current ranged from 5 to $115 \mathrm{~A}$ in each plug, with trapped beam power of 20 to $100 \mathrm{~kW}$ per plug. In the second part of this experiment, the neutral beans on the west end of the machine : re not operated, and a low $(\sim 50 \mathrm{~A})$ current of neutral atous was injected into the east plug. The trapped besm power was 20 to $30 \mathrm{~kW}$. The e-beams were again injected :nto the machine, and the plasma properties were measured.

The experiments and the resilts are discussed below, primarily in terms of the effect of the e-beams on the turbulence level and on the electron temperature of the plasma. Evidence for the propagation of the beam(s) through the length of the machine is given.

\section{INJECTION OF ELECTRON-BEAMS INTO THE TANDEM MIRROR CONFIGURATION}

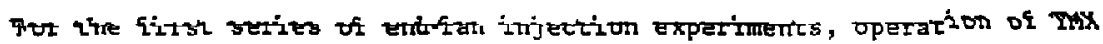
with approximately $100 \mathrm{~A}$ of neutral deuterium gas injected into each plus produced a tjpical tandem mircor plasma with a zepresentative turbilence level, e.g., $0.2 \mathrm{~V}$ peak-to-peak ia the east plug as measuxed on the "total" If probe. The e-beams were injected into the turbulent, steady-state plasma at a power level of several hundred kilowatts per beam. No effect on any meadured plasma property was found. The measured quantities included density in edch section of the machine, diamagneti6n, and electron zemperature. There was no observable effect on the turbulence of the plasma.

The neutral-beam current injected into the machine was then $1 e^{\text {whered }}$ to 50 to 70 per plug. The experiment was repeated with increasing levels of power 


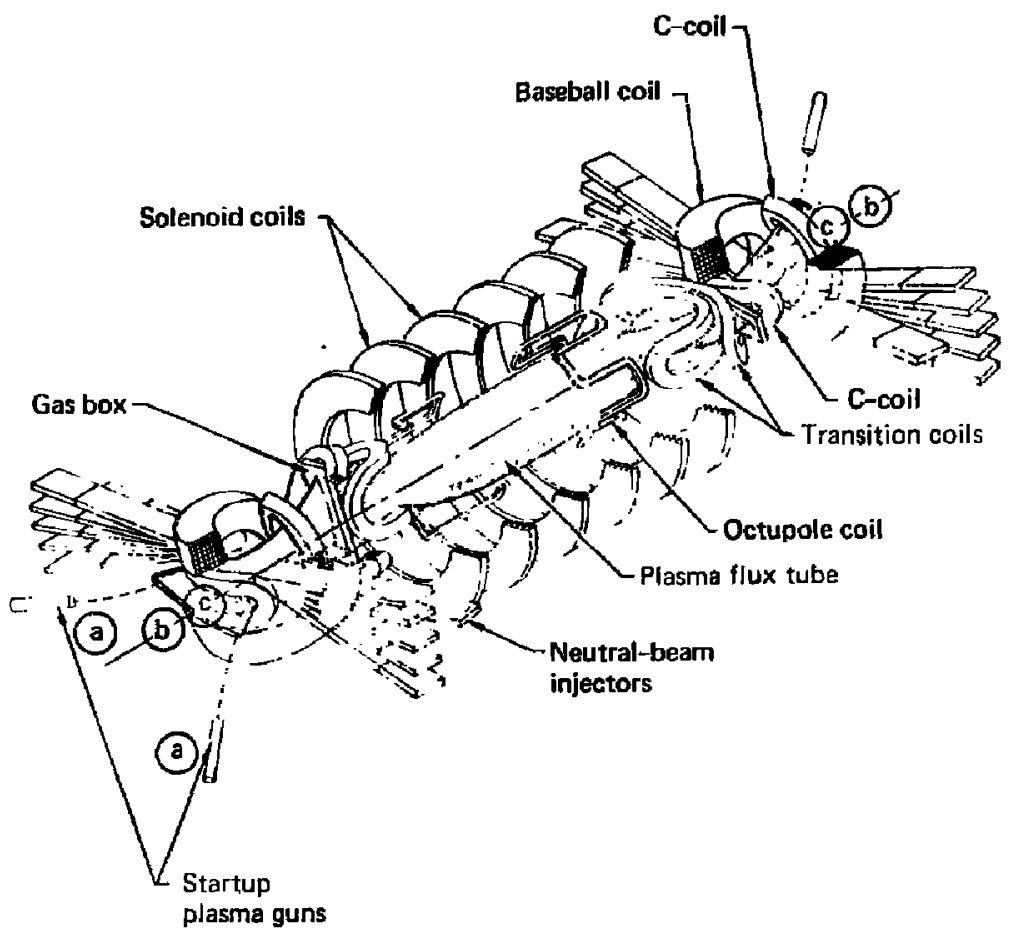

FIG. 1. Schematic of TMX indjcating e-gun positions. Points marked are (a) positions of guns for end-fan experiments, (b) positions of guns for first axial-injection experiment, and (c) positions of guns for second axialinjection experiment. 


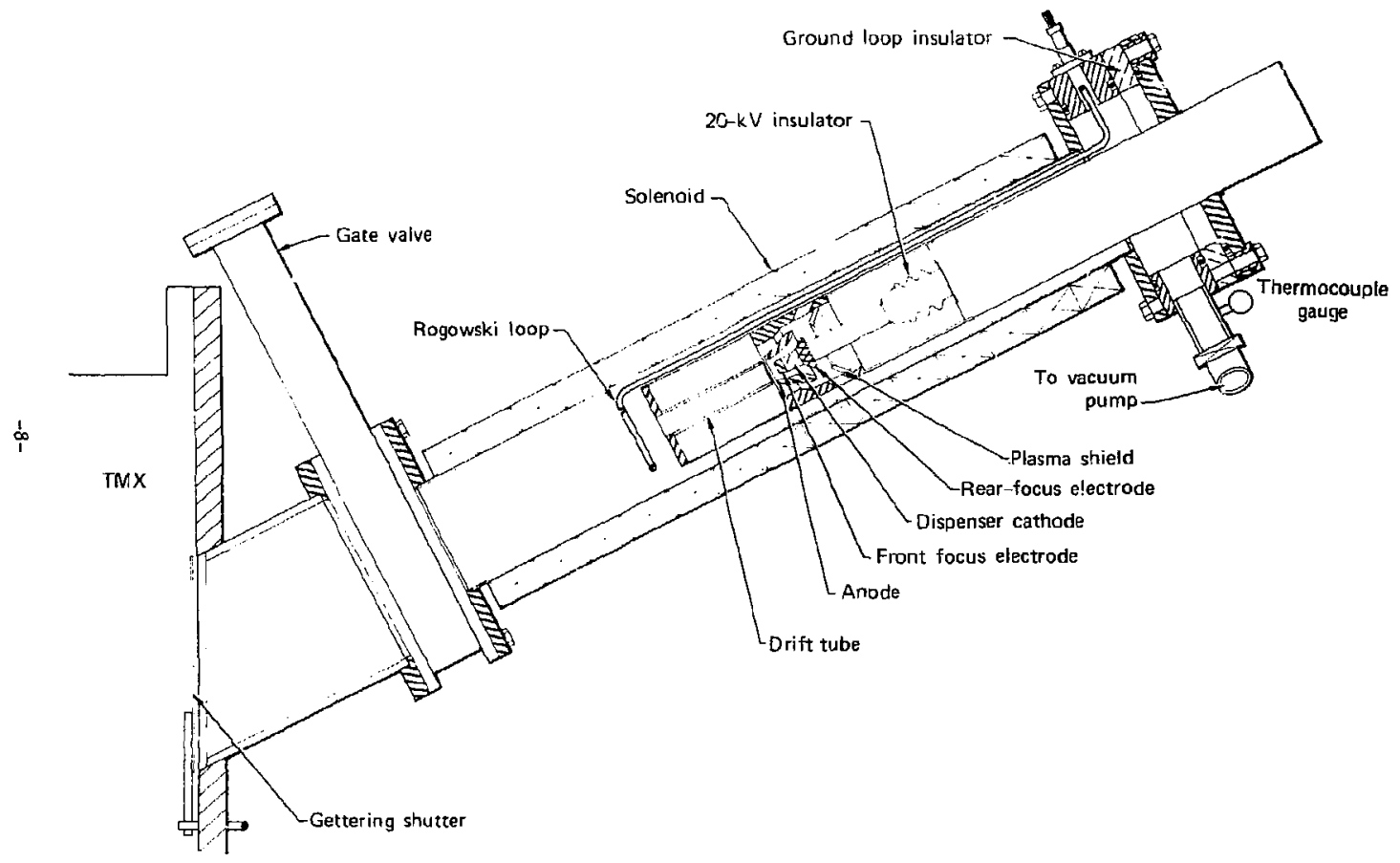

FIG. 2. Schematic of e-gun assembly. 


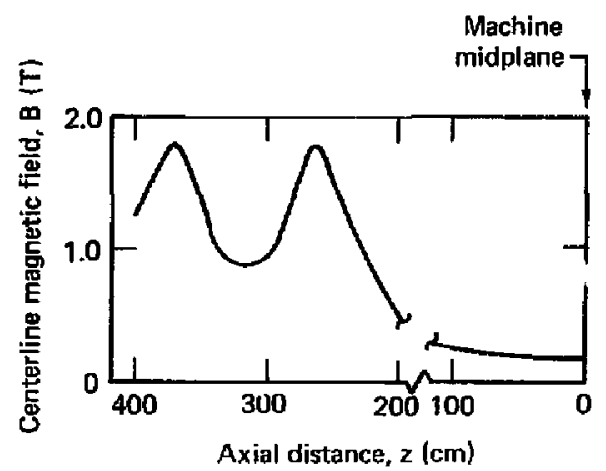

FIG. 3. Axial variation of the centerline magnetic Eield in TMX. 
from the e-beams, eventually reaching approximately $2 \mathrm{WW}$ of injected power ( $30 \mathrm{kV},+30 \mathrm{~A}$ per beam). Operation at the relatively low injected neurvalbeam current resulted in densities of 1 to $2 \times 10^{13} \mathrm{~cm}^{-j}$ in the east plug. The if level in the p!ug was correspondingly low. Again, injection of the e-beams had no effect on the gross plasma parametere of the machine (density, energy content, flow rates, etc.); this tine, however, a burst of rf was noted on the probes in the central cell and the east plug. No if probes were available in the west plug. For all shots where the e-beam was fired, the if level, as measured by an tf probe located radially $30 \mathrm{~cm}$ from the cencer of the eact plug, ilacreaset significantly for the duration of the three-beam pulse (the pulse length varied between 0 and $10 \mathrm{~ms}$ ). Shot 19 (e-beam off) and shot 22 (e-beam on) are repres antarive and can be compared. The neucral-beam currents and densities for the two shots were nearly identical, as can be seer by the secondary emission detector (SED) signals and th a beam sum measurement in Fig. 4. In spite of the large aignal on the untiltered total if probe (see Fig. 5), which has a response up to $\sim 50 \mathrm{MH} z$, a decrease in power in the rundamental and its harmonics was found with e-beams as shown in Figs. 6(a) and $6(b)$. The number of shots in this sequence for which the time interval of recording high-frequency dara overlapped the e-beam pulse was limited; shot 22 mentioned above, shot 23, anc shot 24 exnibited a dectease in the power in the fundamental and the first two harmonics; no shot out of more than 10 in the same density range in which the e-beam was not pulsed showed an abnormally low level of $r f$ power in the fundamental and its observed harmonics. One shot during which the e-beams did not fire and which had a 507 lower plug density did exhibit low rf of a similar nature.

\section{SINGLE-PLUG INJECTION}

For the secotd series of end-fan injection experiments, the neutral beims that power the west plug of TMX were turned off, and ifelatively low current (50 A) of neutrai atoms was injected into the east plug. The purpose of operating with only one plug was to allow comparison with the experiments performed on 2XIIB. As discussed previously, the effects abserved in those experiments were more substintial than the results just described for injection into the normal tandem airret configuration. 

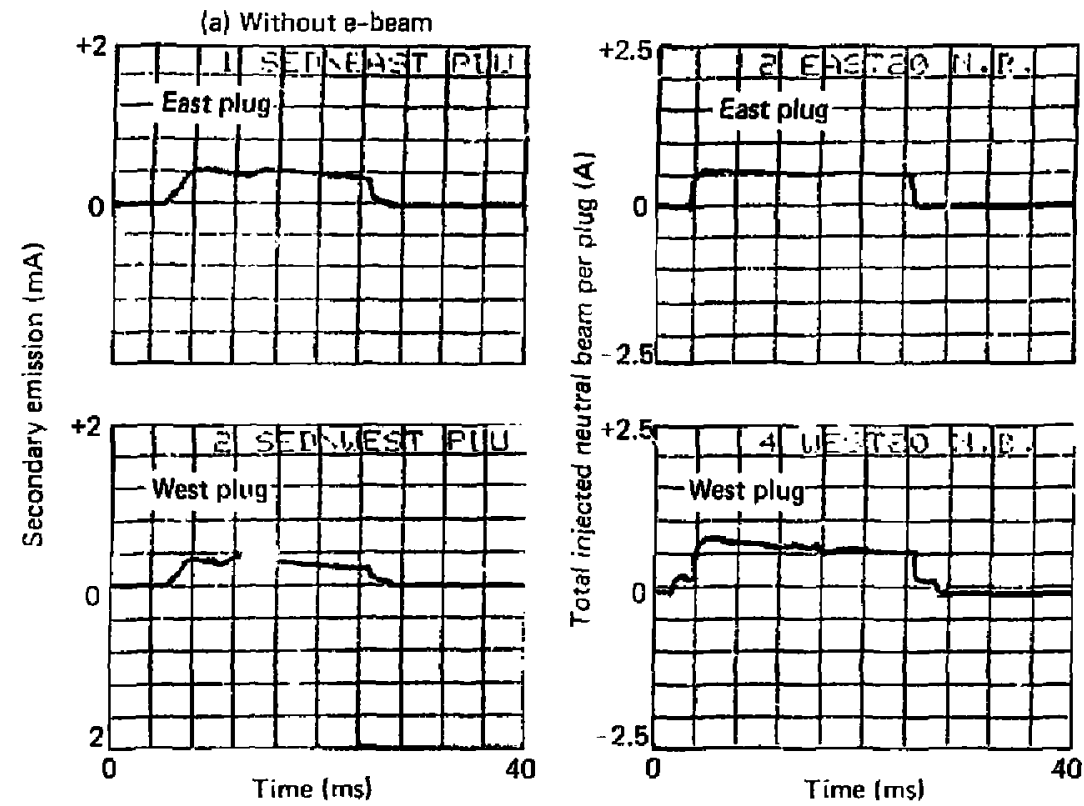

(b) With e-beam
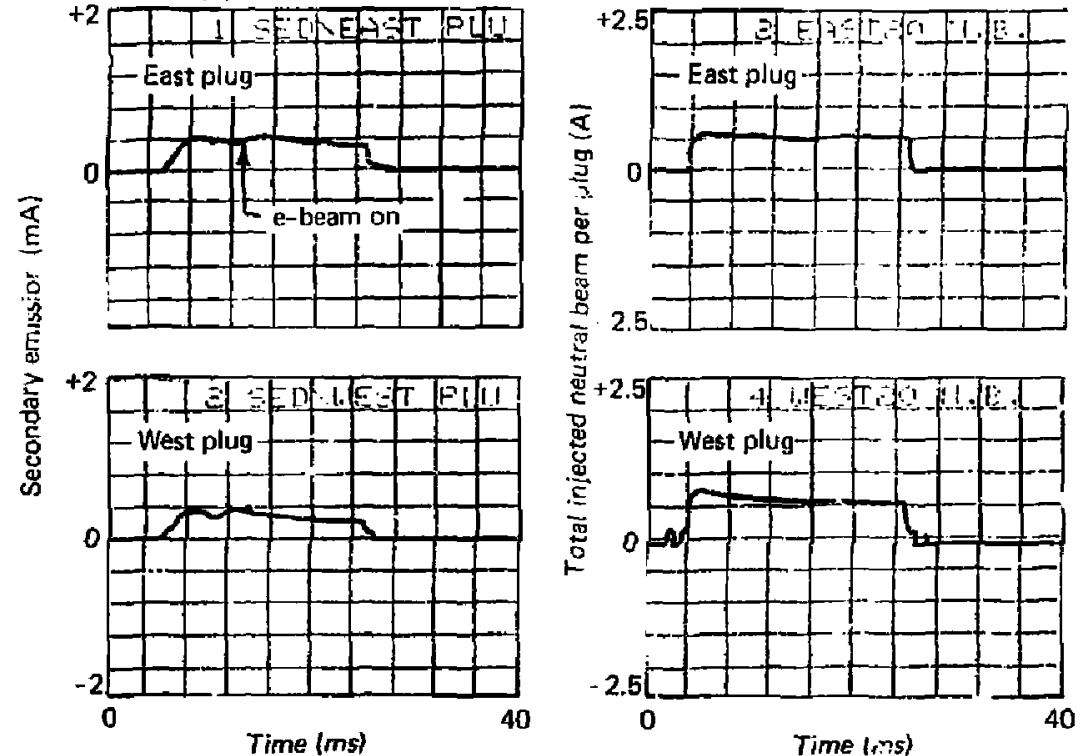

FIG. 4. Injected neutral beam current and secondary emission signed for east and west plugs without (a) and with (b) e-beam injection for siots 19 (a) and 22 (b), November $27,1979$. 


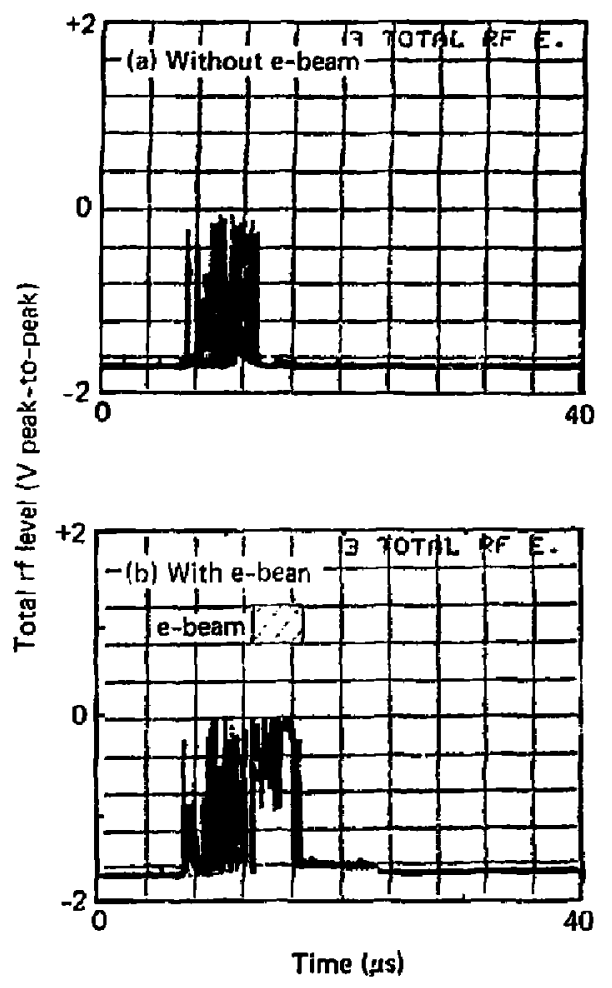

FIG. 5. Total rf level in east plug for shots 19 (a) and 22 (b), showing the effect on measured if due to e-bean injection. 


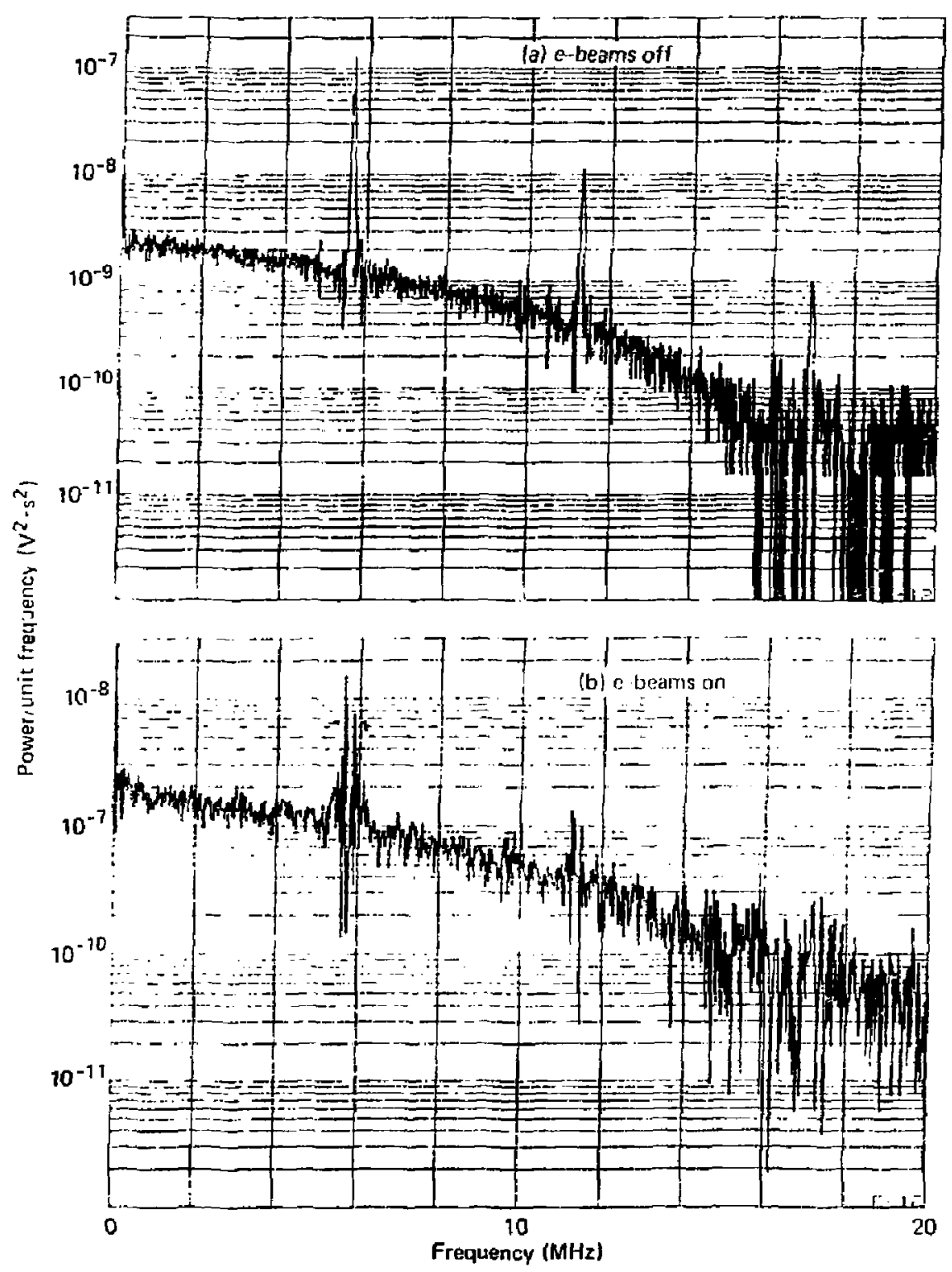

FIG. 6. Frequency spectrum For shots 19 (a) and 22 (b), showing a reduction in fundamental and harmonic ion cjelotron frequencies coincident with e-bean injection. 
The plasma for this : aries of tests was characterized by low density $\left(n=0.7\right.$ to $\left.1.3 \times 10^{13} \mathrm{~cm}^{-3}\right)$. The rf turbulence wonld in general turn of $f$ when the streaming-plasma guns jere turned off, and the plasma would begin to decay. The injected neutral-beam current would not adequately sustain the plasma against inherent losses. Shot 41 , shown in Fig. $7(a),(b)$ and $(c)$, is typical. The central-cell deisity would cypically increase for an additional $2 \mathrm{~ms}$, until $\mathrm{t}=\mathbf{2} \mathrm{ms}$; at that time, both the central-cell plasma and the plug plasma would dec.ry within 0 to 2 ms.

This behavior does not correspond to that of 2XIIB. As the stresmingplasma guns were turned off in that machine, the plasma would decay rapidly $(\tau \approx 0.5 \mathrm{mg})$ and bscome nighly turbulent. Ir TMX, the plasma would of ten become quiescent or operate at a low turbulence level. The differences between the two moshines are the amount of neutral current injected (50 A in this experiment, 300 to $400 \mathrm{~A}$ in $2 \mathrm{XIB}$ ) and the presence of the central cell in TMX. The central cell could well serve as a source of warm jons that would stabilize the machine for the small bean curreat that was injected.

We found that injection of the e-beams at $t=11.0 \mathrm{~ms}$ produced no effect on Lhe abserved powor in the fundamental and first two harmonics of the observed frequencies, in contradiction with the results described abo' $e$ for TMs. Again, however, a high level of if appeared on the "total" if prots. The lowlevel If would be preseat for some shots and not for others; no correlation with the e-beams existed.

The electron temperacure was measured during the decay of the plasma (at $11.5 \mathrm{~ms}$ ), and an increase in electron temperature was found for the ahots in which the e-beans were fired (again at $t=11.0 \mathrm{~ms}$ ). A set of 9 shots, faur with e-beams and five without, showed that the electron temperature increased from $94 \pm 20 \mathrm{eV}$ to $142 \pm 18 \mathrm{eV}$ when the e-beams were injected into the plasma,

\section{PROPAGATION OF THE ELECTRON-BEAM}

In view of the sparse results obtained wien the e-beams were injected into the tandem mirror configuration, it is reasonable to ask how well the beams propagate through the TMX plasma. Several relevant diagnostics were not available on November 28,1979 , when most of the end-fan injection experiments were performed, Operation of the e-beam on Jecember 11,1979 , with the machine in a typical tandern configuration yielded evidence of propagation. The data 


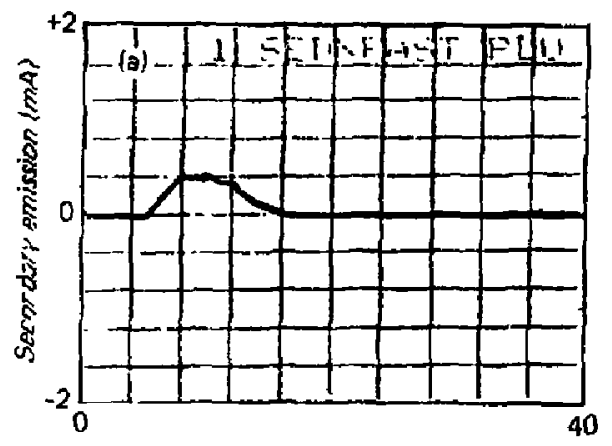

Tirre [ms!

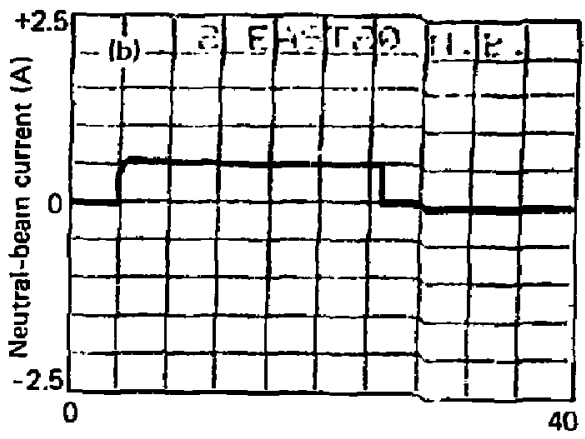

Time (ms)

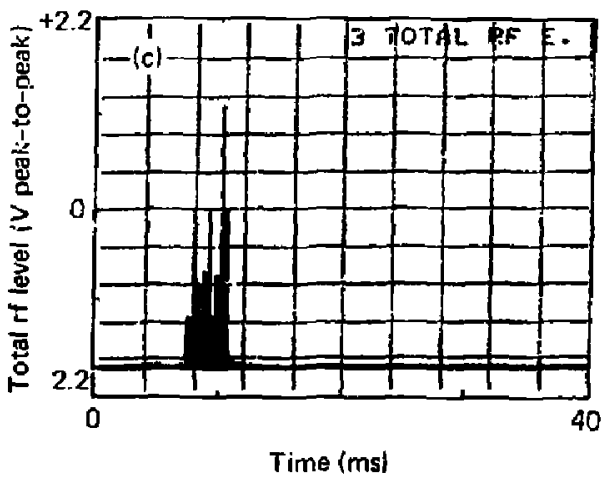

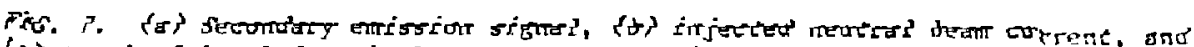

(c) total rf level for single-plug operation (shot 41, November 28, 1979 ). 
consisted of the signal on the west end-loss analyzer (EJA) and the soft $x$-ray diagnostics on the west plug. In Figs. 8 and 9 , the signals obtained during shot 41 are shown. As shown in Fig. 9, the e-beam pulse begins at $t=15$ ms and is sustained at a continuously decreasing level for $10 \mathrm{~ms}$. During this time, the Ela signal is driven negative, indicative of an electron current, and the soft $x$-ray detector (Be filter, plastic acintillator, and photomultiplier tube) shows an enhanced $x$-ray signal. It is clear from other shots that the $x$-ray signal that corresponds to the e-beam pulse is not solely a function of plasma density in the machine. At least part of the signal results from the intraction of the e-beam with material surfaces. It can be shown from the theory that instabilities will develop and grow as the e-beam propagates from its origin at the end wall into the end plug aiong the fanning magnetic field lines. However, the data show that part of the e-beam does propagate through the length of the TMX plasma. The end-loss analyzers map to a radial position of $1.5 \mathrm{~cm}$ in the plug center. Hence the analyzer signal is evidence of either beam/plasma interaction or magnet misalignment. If we assumed that the beam spreads in a uniform manner, we can obtain a coarse estimate of lie transmitted e-beam current from the ELA signal. The signal obtained would be the result of an incident electron current denaity of $\sim 0.4 \mathrm{~A} / \mathrm{cm}^{2}$, normalized to the plug midplane. If se assume a uniform current density distribution over 3 ratius of $5 \mathrm{~cm}$, the observed gignal implies an e-beam current of $\rightarrow 30 \mathrm{~A}$, in rough agreement with the injected current. The upper 1 imit to thr energy that can be deposited is limited to roughly one-half the injected energy. This limit is due to the decrease in the positive slope of the velocity distribution function as cine jeam loses energy. ${ }^{6}$ It is also apparent that the actual energy deposited is much less; otherwise the e-beams, which can inject $\sim 2 \mathrm{MW}$ into the plasma, would significantly affect the energy flow in the $M x$ machine and hence its frross parameters.

\section{SUMMARY OF END-FAN INJECTION EXPERIMENTS}

Injection of e-beams through the end fan of the east plug does not appear to affect the measured plasme properties of TMX at all if the neutral-beam current injected per plug is in excess of $100 \mathrm{~A}$. The ion cyclotron fluctuations show no indication of either increasing or decreasing. 


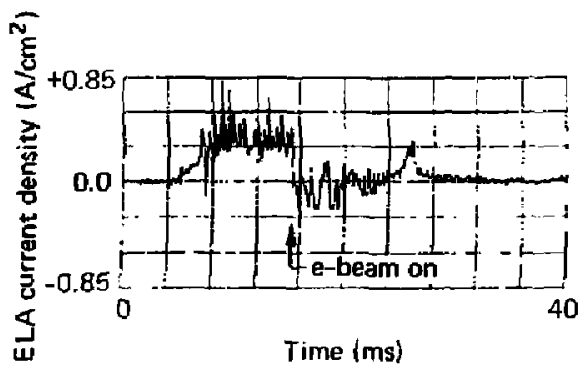

FIf. B. End-loss analyzer (ELA) current deasity normalized to plug midplane showing a flux of electrons due to the injected e-beam (shot 4l, December ll, 1979). 

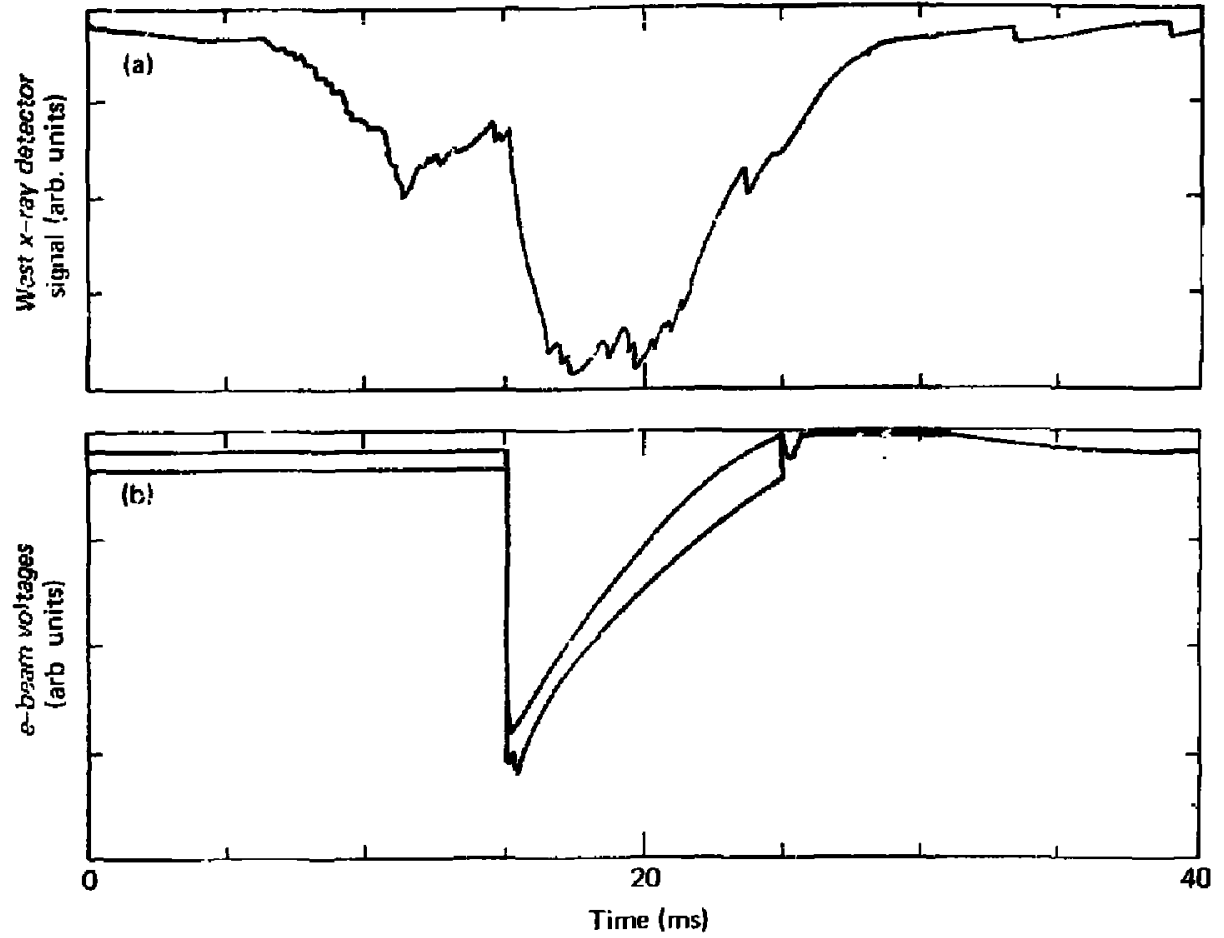

FIG. 9. (a) Soft $x$-ray signal, and (b) e-beam voltages showing correlation of $x$-rays signal from the west plug with e-beams injected from the east plug (sirot 41, December 11, 1979). 
If TM is operated with low power and low turbulence, injection of the e-beams is indicated by an increase in the signal from an unfiltered rf probe located near the plasma. There is no effect on gross plasma parameters such as Iine density or energy. The fundamental and the first harmonic of the excited trequencies were not monitored reliably for these shots because of a mismatch between frequencies and the band-pass filters employed. For the only three shots for which high-frequency data were acquired during an e-beam pulse, the power in the fundamental and the first two harmonics was unusua'ly low. That did not happen for shots having equal densicies in which the e-beams were not fired. It was apparent that the e-beams did affect the frequency spectrum. Operation of TMX wath neutral-beam injection into the east plug only showed no similar behavior. To correlation between the observed ior cyclot-on flsctuation spectrum and the e-beams was found. We note that the fluctuation level of $\mathrm{TMK}$ when it is operated at low beam power is weak and intermittent, and that a small perturbation of the plasma can cause either the appearance or disappearance of the fiuctuatione. At iow level, the fluctuations do not have a measurable effect on the gross plasma parameters. Irjection of the e-beams into the plug under the above conditions increases the electran temperature from $94 \pm 20 \mathrm{eV}$ to $142 \pm 18 \mathrm{ev}$. High-energy $x$-ray diagnostics were not available for these tests.

\section{AXTAL-INJEGTION EXPERTMENTS}

For the series of axial-injection experiments, ane e-beam gun was placed or the machine centerline on each end of tile machine. In the first such experiment, the guns were positioned outside each extreme mirror point at a placs where the magnetic field was $4 \mathrm{~kg}$ ( $30 \mathrm{~cm}$ from the extreme mirr point). In the second set of experiments, the guns were moved up to within 5 cm of the mirror point, and again the e-beams were injected into the machine. Some of these experiments were employed to generate a start 4 plasma by injecting an e-beam into neutral gas. The results of these experiments are described in more detail in the following paragraphs. 


\section{ELECTRON-BEAM INJECTION AT 4-kG POSITTON}

For this experiment, the guns were located $\sim 30 \mathrm{~cm}$ from each outer mirror point at $B=4 \mathrm{kG}$, and e-beams were injested along the centerline $0^{\prime} i$ the machine. The plug densities for these experiments were $\sim 10^{13} \mathrm{~cm}^{-3}$ with a centrat-cell plasma dengity of a few $10^{12} \mathrm{~cm}^{-3}$. Data were obtained over a range of machire parameters (beam power, gas feed) and e-beam voltages, curronts, and pulse duration. Shot 42 has been chosen as being representative for this set of experiments. Some of the reduced data for that sho: are included in Fig. 10.

The data showed that the e-beams did not affect the density, turbulence leve 1 , diamagnetism, and end flows in the machine. Electron temperature measurements were not available during this sequence of tests. However, none of the quantities that depend in part on the electron temperature near the machine centerline, such as end-loss flow rate, plug potential as measured by the ElA, turbulence level in the east plug, and ultraviolet (uv) emissic: from 0 VI, showed changes that could be attributed to a change in electron temperatures due to interaction with the injected e-beams. It is interesting that the increase in if as measured on the unfiltered $r f$ probe located at the boundary of the east-plug plasma did not appear in this set of experiments as it did in the end-fan injection experiments. If the t-beams were pulsed through the machine with no plasma present, the if probes in the central cell and in the east plug would pick up rf oscillations from the beam located on the west eno of the machine. No rf diagnostics were employed on the west plug,

\section{ELECTRON-BEAM INJECTION 5 cm FROM OUTSIDE MIRRORS}

Next, the e-guns were moved as far towerd the mirror point as was physically possible: the mirror point was $5 \mathrm{~cm}$ from the front of the e-gun. The cathode of the east gun had been poisoned during a TMX vacuum loss, and only the west e-gun was operational.

Operdtion of the guns in this position did produce a marked effect on the plasma. With densities of 1 to $2 \times 10^{13} \mathrm{~cm}^{-3}$ in the plugs, results showed that the e-beam from the west plug would cause an increase in the east plug density ard amall increase in the radius of the central-cell plasma. The line density through the center of the west plug either did not change or 


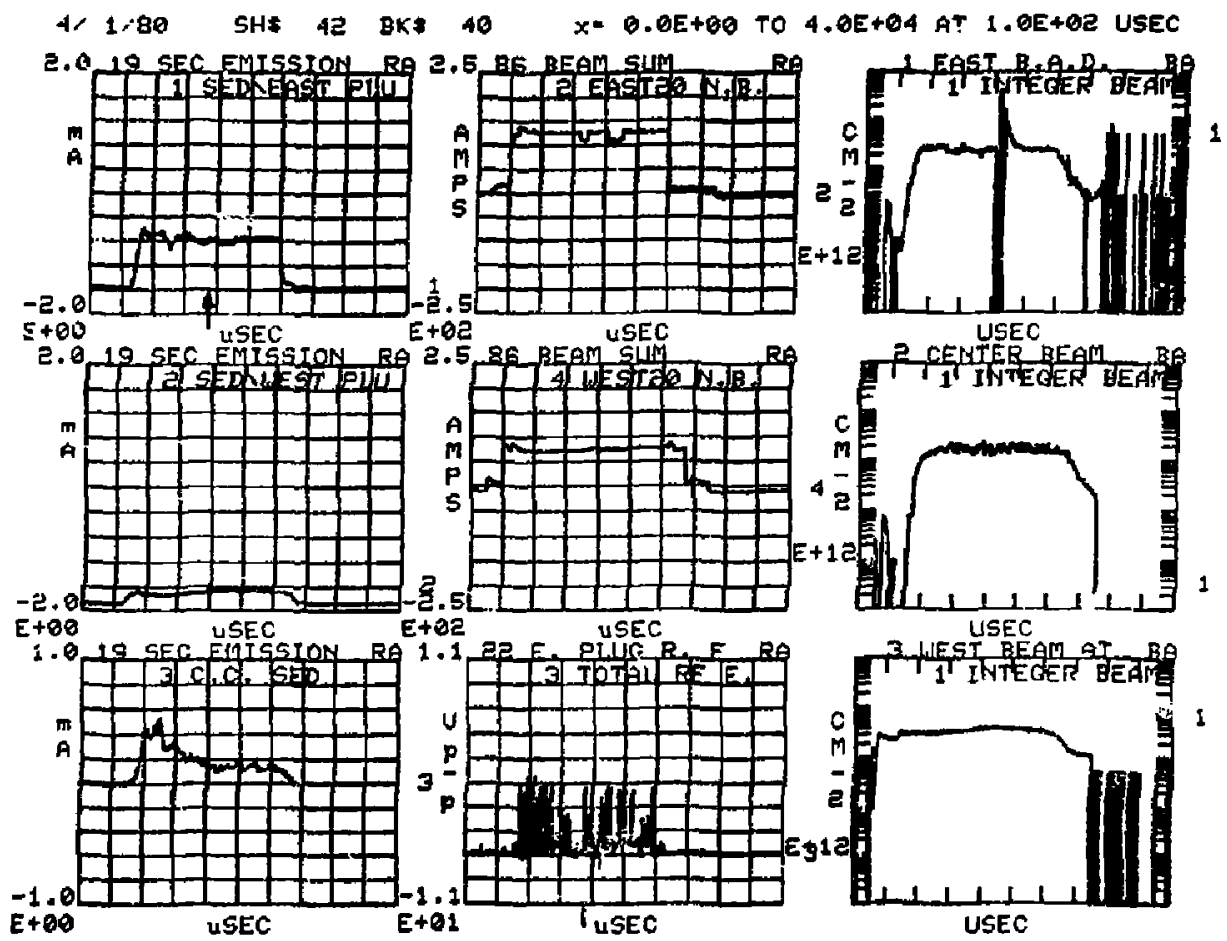

FIG. 10. Reduced data for shot 42 , April 1, 1980, illustrating the diagnusics employed for the e-beam experiments. 


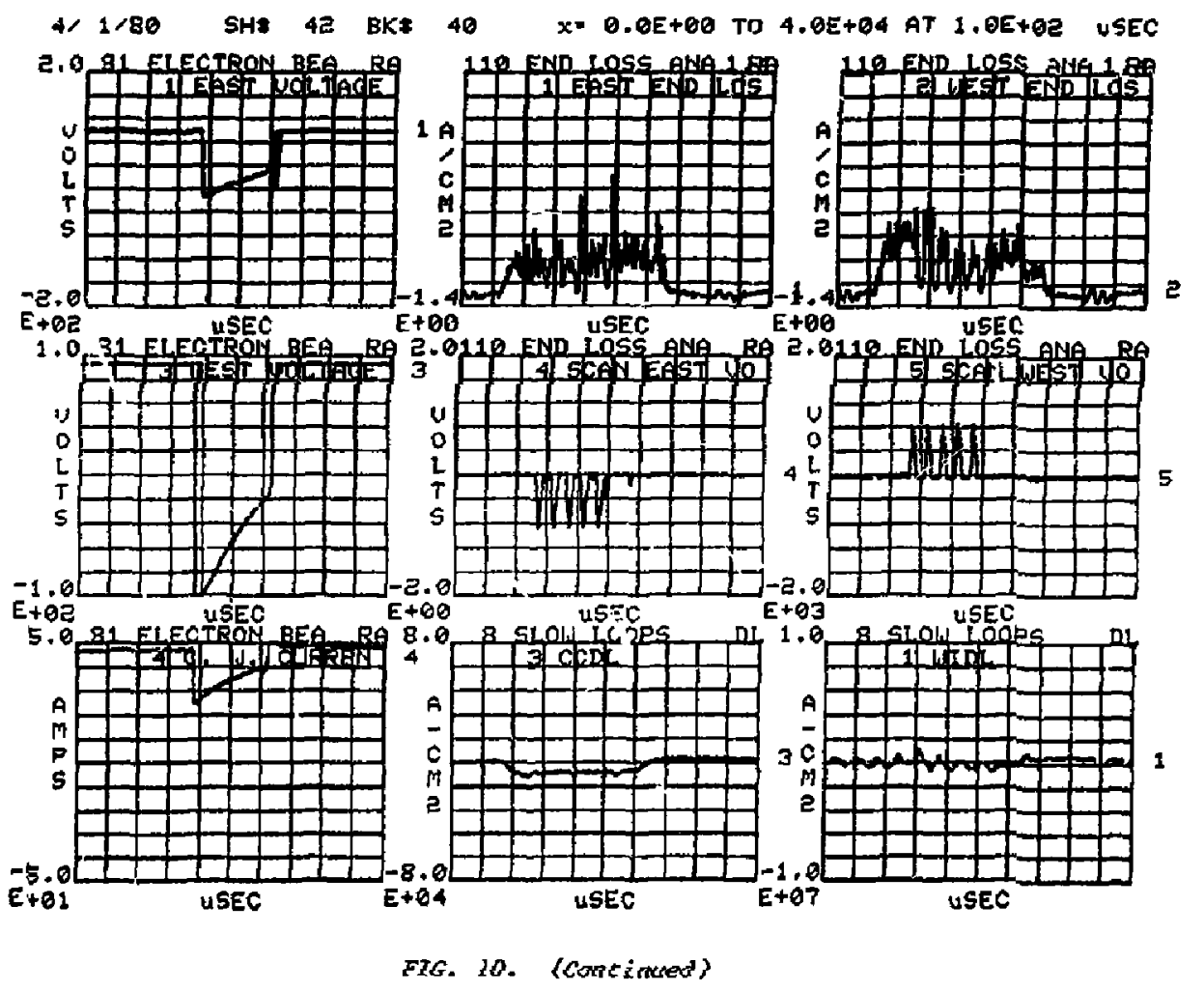




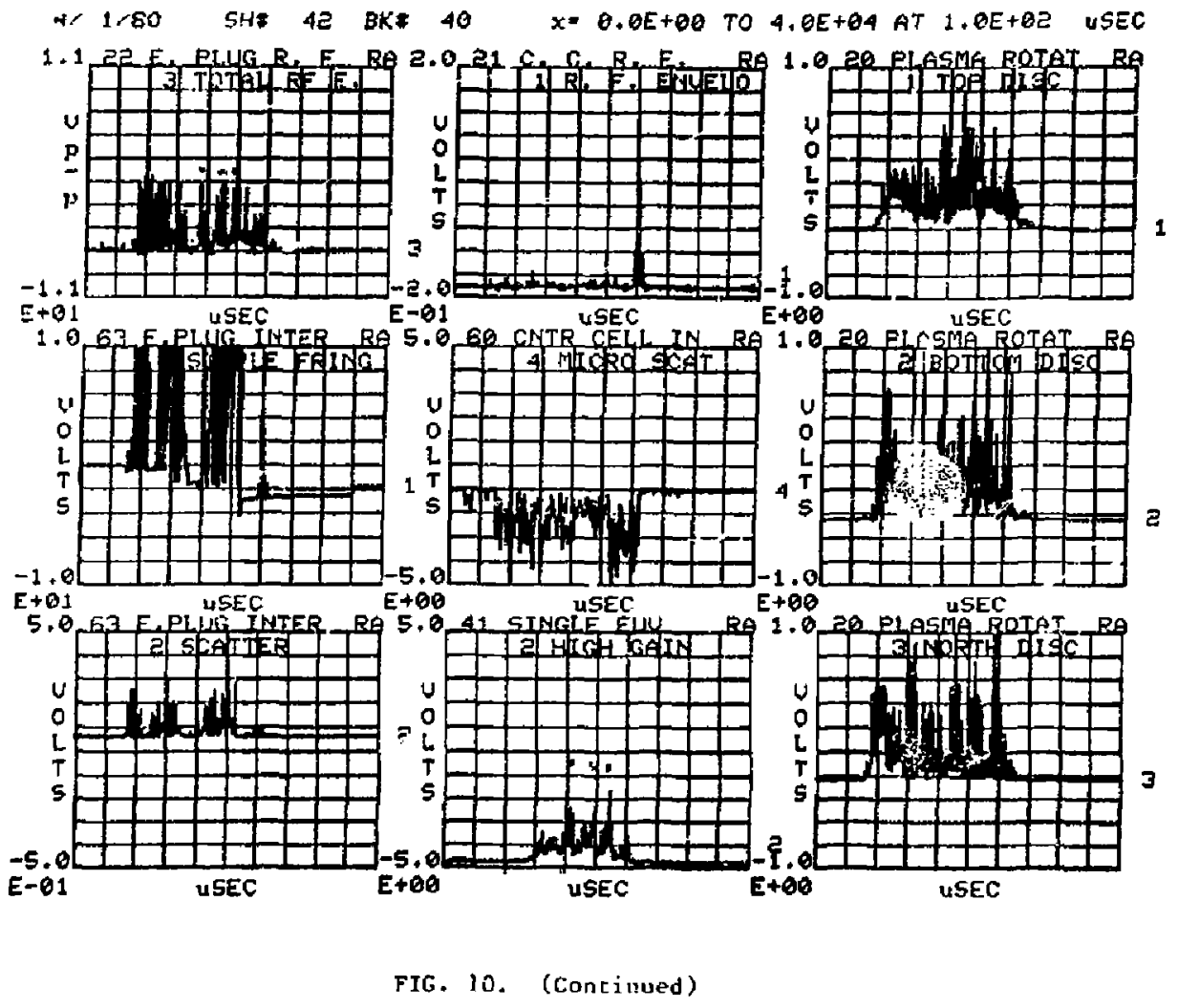




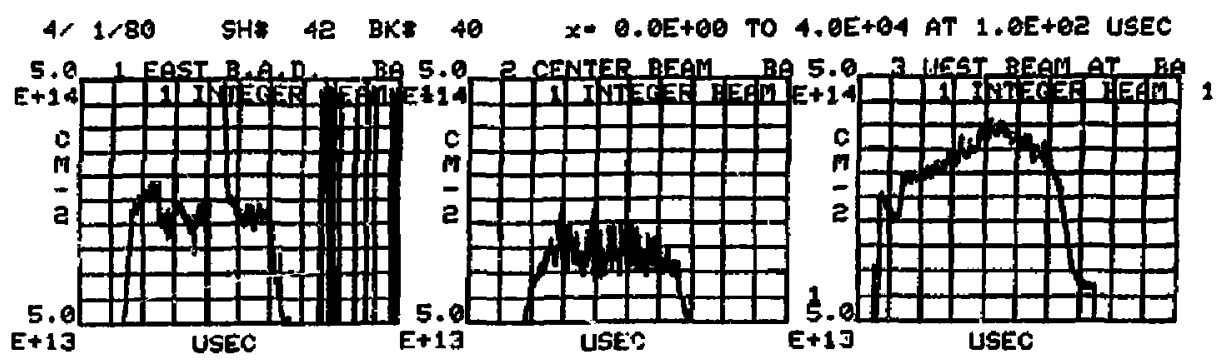

FIG. 10. (Continued) 
decreased slightly. The electror. temperature in the east plug decreased from 80 to $90 \mathrm{eV}$ to 20 to $40 \mathrm{eV}$, in contradiction with the heating that would be expected from the e-beam injection. Examination of the data showed that the density increased 0.5 to $1 \mathrm{~ms}$ after injection of the e-beam; no effect was noted for the first few hundred microseconds after the beginning of the beam pulsiz.

In gateral, the secondary enispion detector (SED) located in the central coll showed that an enhanced signal occurred with a time delay with respect to the beginning of the bears pu 2 se. The change in magnitude of the SED signal did not correspond to a chans. in the measured line density, indicating that the scurce of the enhanced signal could be either uv radiation or a sharpening of the perpendicu'ar velocity distribution of the plasme ions. The single-channel uv spectrometer did not operate when these daca were taien; however, measurements with the normal-incidence spectrometer showed levers of aluminum and oxygen that were higher than normal. A possible source of these impurities could be the insulators of the streaning-plasma guns; we found after the experiment that the streaming-plasma guns had intercepted part of the electron flux from the beems. The east e-gun had also intercepted part of the e-beam from the west e-gun, both the east e-gun and the east streaming-plasma guns featured an eroded area, a horizontal groovi a few mm wide, caused by the incident beam. Again, the question of e-beam propagation through the plasma is ralevant; the e-beams were pulsed regularly with no plasma in the machine and it's possible that the marks were made under those canditions. Shots 16 through 20 of April 9, 1980, showed Erom soft x-tay detectors on the east plug that the beams did propagate through the machine with the plasmf present. In addition, shots from Apri1 10, 1980, when the x-ray detectors failed, showed that the west e-beam would propagate through the machine to the east ELA (shots 28,30 ).

The shots on April 10, 1980, were with a range of plasma densities in the east and west plugs; we found that the severity of the influence of the e-beams on the plug plasmas depended on the plasme density of the plugs. Thus, when the east plug was operated at $n \approx 2 \times 10^{13} \mathrm{~cm}^{-3}$, the effect of the west e-beam would be to lower $T_{e}$ from 80 to 90 et to 30 to $40 \mathrm{e}$ in 1 ms or less and to lower the diamagnetisw of the central cell by 0 to $50 \%$. The rf level of the east plug would largely rema "mutant for shots having an east-plug density $n \approx 2 \times 10^{13} \mathrm{~cm}^{-3}$. The end loss in the east plug would increase for some 
shots, but not markedly. The effect on the density and end loss in the west plug was not in generai noticeable. Though the east SED and beam-attenuation detector both showed greater gignals when the e-beam was pulsed, it is got clear that those increases resulted from an increased plasma density. An increase in uv level or a sharpening of the perpendicular velocity distribution would also increage the signal on each of these diagnostics. Shot 28 is representative, and a sumary plot is shown in Fig. 11 .

As shown in Fig. 12 for shot 30 , decreasing the plasma densicy in $t$ s machine caused the effect of the e-beam to be more evident. The temperature would again decrease to 20 to $40 \mathrm{ev}$, the end loss would double, and the If level, after an initial burst at the beginning of the e-beam pulge, would subside. It is plausible that, because of the low electron temprerature in the east plug, the potential of the east plug decreased with respect to that of the west, and the enhanced end-1oss current resulted from a Ioss of canfinement of central-cell ions. We note that for these shots, the beam-actenuation signals and the SED signals from the east plug decreased with time after the e-begm pulse was initiated, indicating a loss of density in the east plug.

In sumbary, injection of an on-axis e-beam into TMX did not reduce the turbulence level in the TMX plasma except when the guns were located at the mirror throats. In that position, injection of the e-beams would lower the electron temperature in the machine. The probable cause for the cooling of the plasma electron in that case was the generation of gas and impurities as the west bean struck a solid surface such as the east e-gun.

\section{STARTUP EXPERIMENTS}

The TMX machine requires a plasma having a density of 5 to $10 \times 10^{12} \mathrm{~cm}^{-3}$ in each end plug in order to start up using neutral-beam injection of 100-A equivalent current per plug. This plasma density is normally produced by a 5-ms-duration stream from one or two streaming-plasma guns. These guns, though highly effective in generating plasme, are a saurce of various high-z impurities, primarily titanium. If startup on an e-beam-generated plasma vere posaible, and could be shown to be reliable, the e-beams would provide an attractive al lernative to the streaming-plasm guns. The 2XIIB plasma had previously been started on an e-beam-generated plasma. ${ }^{4}$ We therefore designea an experiment whose primary purpose was to start the plasma with the e-beams; 


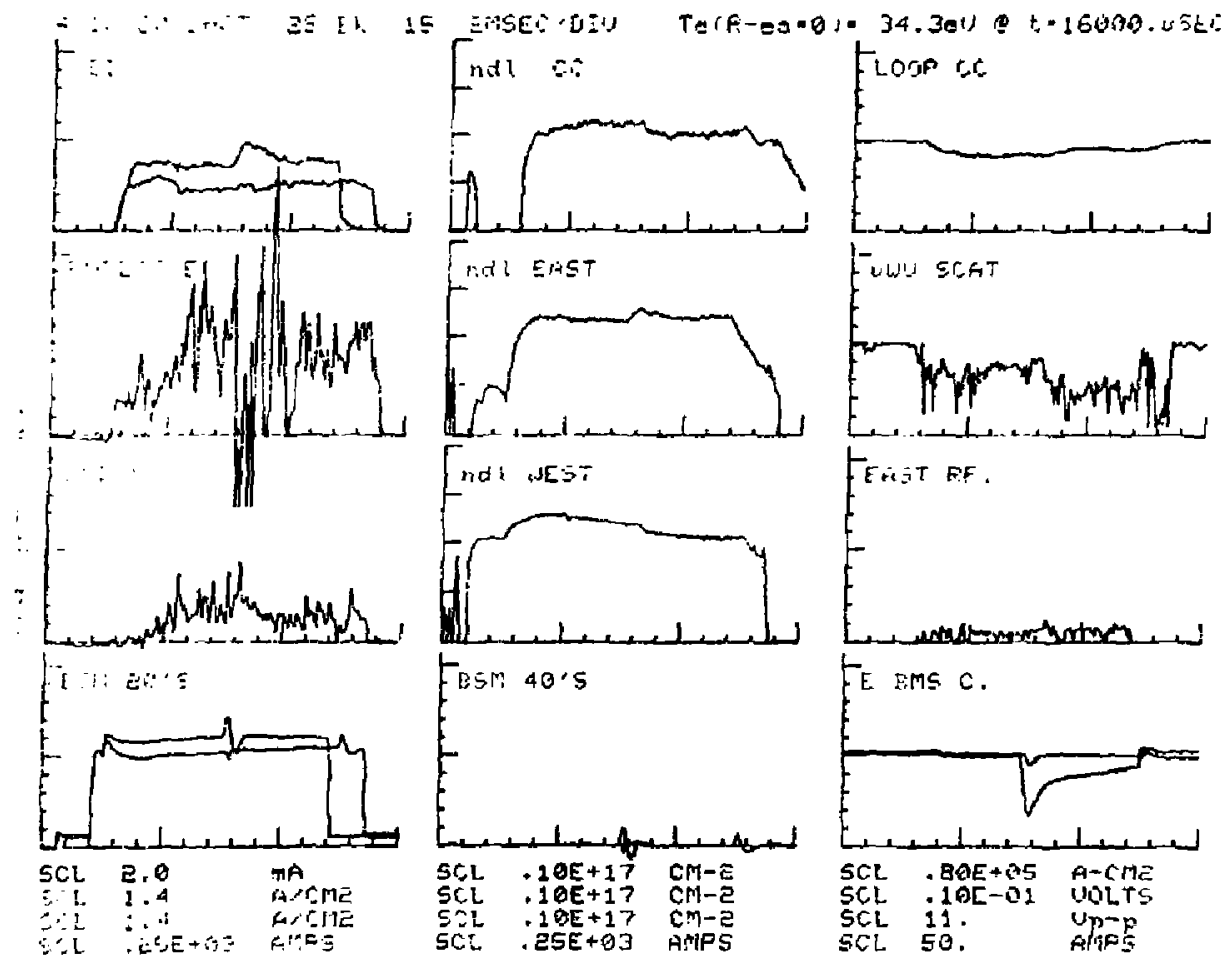

FIG-11. Sumary plot showing effect of e-beam injection with east-plug density $n \approx 2$ y $10^{3} \mathrm{~cm}^{-3}$ (shrt 30, April 1 , 1980). 


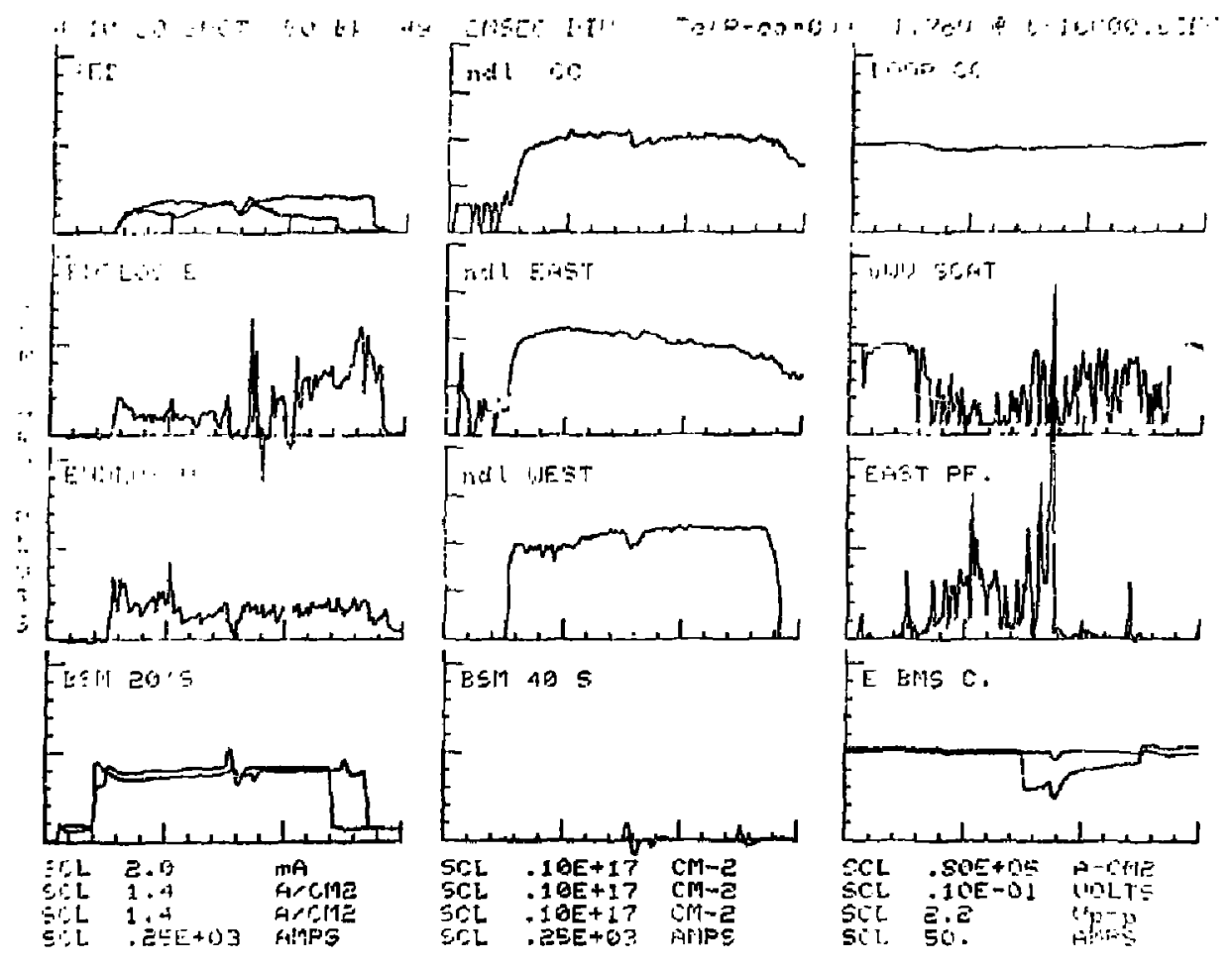

FIC. 12. Sumary plut showing effect of e-beam injection with east-plug density $n=1 \times 10^{13} \mathrm{~cm}^{-3}$ (shnt 30, April 10, 1980). 
if the plasma did not start up, the secondary aim was to assess the requirements for startup with the e-beams.

In the experiment fescribed here, only the east-plug magnetic field and neutral beams were operated. The e-beam was injected from a gun positioned as near to the magnetic mirror point as was possible, with $5 \mathrm{~cm}$ between the tip of the gun and the mirror point.

To show that the presence of the central-cell plasma was not essential for buildup and maintenance of a stable plug plasma with the neutral-beam current available for these tests, the east plug was first started on a plasma from a streaming-pla.iud gun. The results were positive, as shown in Fig. 13(a).

Electron-beam-gerercated plasmas were then produced by injecting the e-beam into the neutral deuterium gas flowing from a gas source located at $1.4 \mathrm{~T}$ outside the mirror point on the opposite side from where the beam was injected. We founo that the density of the beam-generated plasmi was a function of the flow of neutral gas from the gas source. Increasing the gas flow to the maximum available, an estimated $200 \mathrm{Tor}$.litre/s at the $1.4-\mathrm{T}$ point, produced a plasma density of approximately 1 to $3 \times 10^{12} \mathrm{~cm}^{-3}$, below that required for startup. The results are shown in Fig. 13(b). An increase in plasma density by a factor of two to five would be adequate for startup in TMX, in accordance with the experience acquired frot startup with streaming-plasma gun plasmas. such an increase could be attained by increasing the neutral gas density in the region of the magnetic field ninimur, for example, by direct injection of gas into that regien.

A possibly significant difference between the $T M X$ and the $2 \times I r B$ e-beam slartup experiments is in the location of the gas source. In the $2 X I 18$ experiment, the gas source was located at a mirror point. In the TMX experiment, the source was outside the mirror. The location of the gas source relative to the mirror affects the flow of plasma and neutrals into the confinement region.

\section{SUMMARY OF THE THEORY OF ELECTRON-BEAM/PLASMA INTERACTION}

The interaction of an e-beam wich a plasma has received extensive theoretical treatment in the linear approximation. ${ }^{7,8}$ within this approximation, the modes of the instabilities can be identified and the growth rates can be computed. Since many modes exist, comparison with experimental results can be difficult; however, " has been the experience that the mode having the greatest linear grouth will be the mode observed in an experiment. 

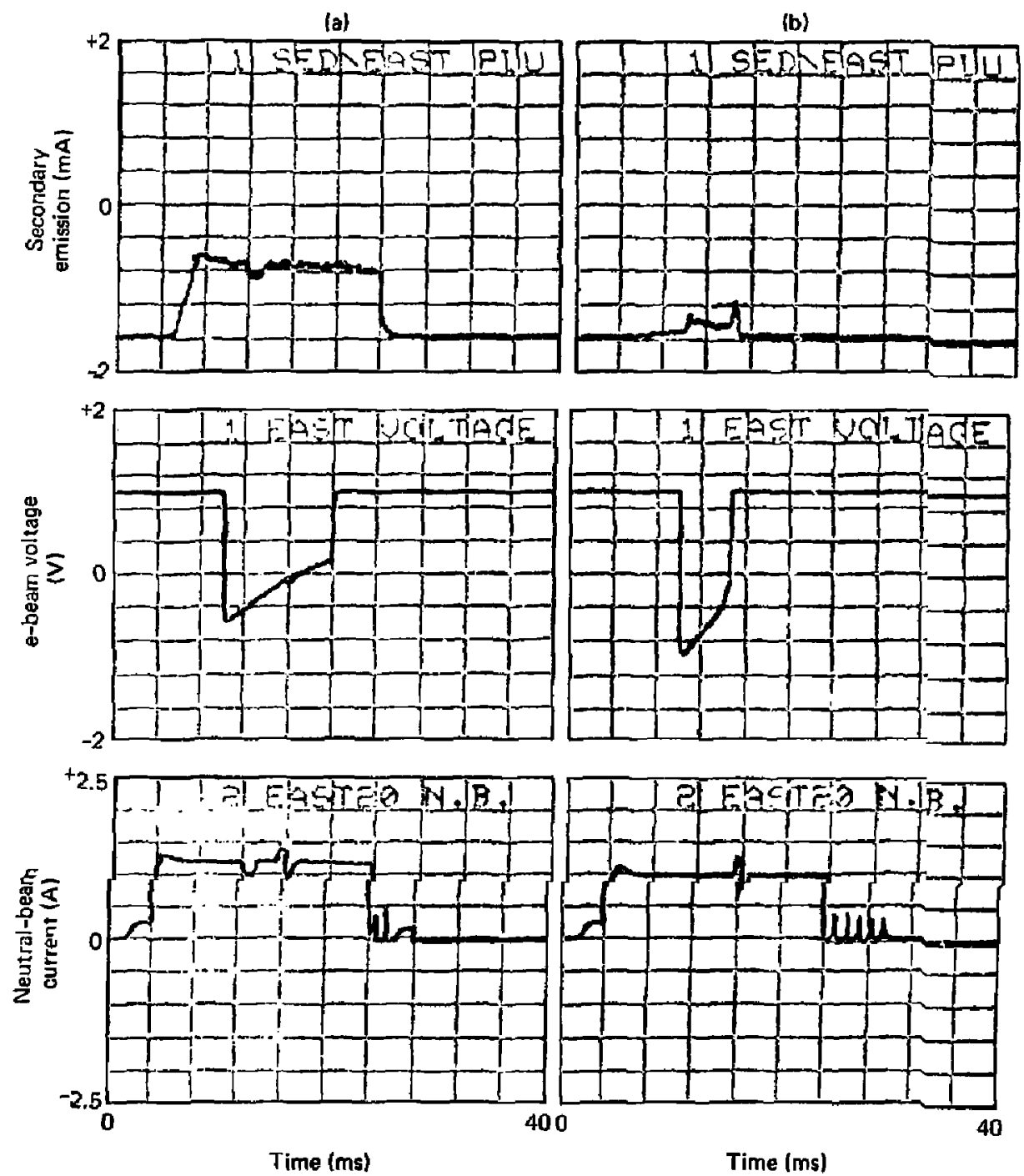

FTG. 13. The signals from the secondary emission detector, the e-beam voltage, and the injected neutral beam-current are shown for a aingle-plug startup experithent on a streaming-plasma-gun (a) and an e-beam-generated plasma (b). 
Using this observation, Seidl ${ }^{9}$ has computed the frequercy, growth rate, and wave number of the most unstable waves as a function of beam and plasma Pârameters. The general features of the cold-beam/cold-plasma interdction are representative of the experiments discussed here. Inclusion of fintle plasma temperature does not greatly alter the results. The e-beam is assumed to be injected along the ragnetic field lines for the discussion below; this assump$t i$ an corresponds to the experimental situation. The discussion does not apply to helical beams, i.e., beams having a perpendicular yelocity distribution with a positive slope.

It is an experimental observation and consistent with theory that the resonances of the cold-beam/plasma interactions satisfy the synchronism condition

$$
\therefore-m \omega_{c}-k_{z} v \approx 0
$$

guite we 11. 10 Here $w$ is the frequency of the excited waves, ${ }_{c}$ is the electrol. cyslotion frequency, $m$ is a mode number, $k_{z}$ is the wave number in the direction of the magnetic field, and $v$ is the beam velocity. Solving the plasma dispersign relation with the synchroniso condition results in a relation betwcen the extited frequency $w_{r}$ and the growth rate $w_{i}$, the plasma parameter $w_{p} / s_{c}$ (where $\omega_{p}$ is the plastra frequency), the mode number $\mathrm{m}$, and a parameter $g=k_{t} v / \omega_{c}$; here $k_{1}$ is the wave number perpendicular to the direction of the magnetic fisld. For the cold-besm/plasma interaction, it is found that only the wave numbers $m=0$ and $m=-1$ result in the growth of unstable waves.

It is generally the case that the waves having the smallest possible wave number will dominate. For small values of $k_{\jmath}\left(k_{\lrcorner} / \omega_{f} \ll 1\right)$, the $m=0$ mode will have the greatest growth rate; the $m=-1$ mode reaches its greatest growth rate for large $k_{1}\left(k_{\perp} V / \omega_{c} \geq 5\right)$. It is an experimental observation' that the growth rate of the instability is generally smaller for the low-frequency $L$ waves $\left(\omega<\omega_{c}\right)$ than for the $H$ waves $\left(\omega>\omega_{c}\right)$, and it is usually the $H$ waves that are observed in an experiment.

The value of $k_{1}$, and therefore of $B=k_{1} v / w_{c}$, is subject to uncertainty due to the variations in plasma cross section as a function of axial diacance. A typical value of $\mathrm{g}$ is, for $k_{\perp} \approx 0.1 \mathrm{~cm}^{-1}, v=10^{10} \mathrm{~cm} / \mathrm{s}$, and $\omega_{c}=30 \mathrm{GHz}$ at $1 \mathrm{~T}$,

$$
g \approx 0.03 \text { at } B \approx 1 \mathrm{~T} \text {. }
$$


Thus, 8 is generally small relative ta unity.

The dependence of the excited frequency $w_{r}$ and the growth rate $w_{i}$ can be shown graphically as a function of the mode number $m$ and the beam and plasma parameters $g=k_{\perp} v / \omega_{c}$ and $\omega_{p} / \omega_{c}$. The graphs for $m=0$ and $m=-1$ are show in Fig. 14(a) and (b).

An important feature of both graphs is the dependence of the excited frequency $", c$ of the $H$ waves on the plasma parameter $\omega_{p} / w_{c} \cdot$ For all values of $\omega_{p} / \omega_{c}$, the excited frequency $w_{r}$ exceeds the larger of $w_{p}$ and $!_{c}$. The upper $1 \mathrm{imit}$ to the excited frequency is the upper hybrid frequency $\omega_{H}=\left(\omega_{\mathrm{p}}^{2}+\omega_{c}^{2}\right)^{1 / 2}$. Since a primary mechanism for efficient energy transfer between the excited waves and the plasma electrons is electron cyclotron damping, the axial position within a given magnetic field configuration where resonant absorption can take place depends upon the wave frequency.

The generation and absorption of waves generated within a magnetic field configuratior and ir plisma having various density distribution can best be discussed by reference to plots of the axial distribution of the frequencies (2) ${ }_{c}$, ${ }^{2}$, and $z^{*}$. It is the main conclusion of this discussion that the results of the inceraction of an e-beam with a mirror-trapped plasma changes in a qualitative fashion as the density of plasma increases and the axial density gradients become greater.

In the limiting case where the plasma density is uniform throughout the magnetic mirror, we can find the range of frequencies created by the beam/pla ma interaction. The high-frequency $\mathrm{H}$ waves have a group velocity that opjoses that of the beam velocity ${ }^{11}$; $i . e .$, the energy propagates in a direction opposite to that of the beam unless the waves are reflected.

The relevant frequencies generated in a low-density $\left(\omega_{p}^{2} \ll \omega_{c}^{2}\right)$, mirror$t$. pped plasma are shown in Fig. 15 as a function of axial position. The frecuency and direction of the generated waves are indicated by an arrow. It is seen that for a low-density plasma, the waves generated within the magaetic mirror will be absorbed at the fundamental electron cyclotron resonance. This absorption m:chenism is in general very efficient and can generate very high energy electrons having energies of up to an order of magnitude greater than the energy of the beam electrons. Even where the density is sufficient to make $\omega_{p} \approx \omega_{c}$, the mechanism of absorption within the mirror can be electron cyclotron resonance, as show in Fig. $15(\mathrm{~b})$. The limiting condition for resonant fundamental electron cyclotron abeorption within a magnetic mirror is 

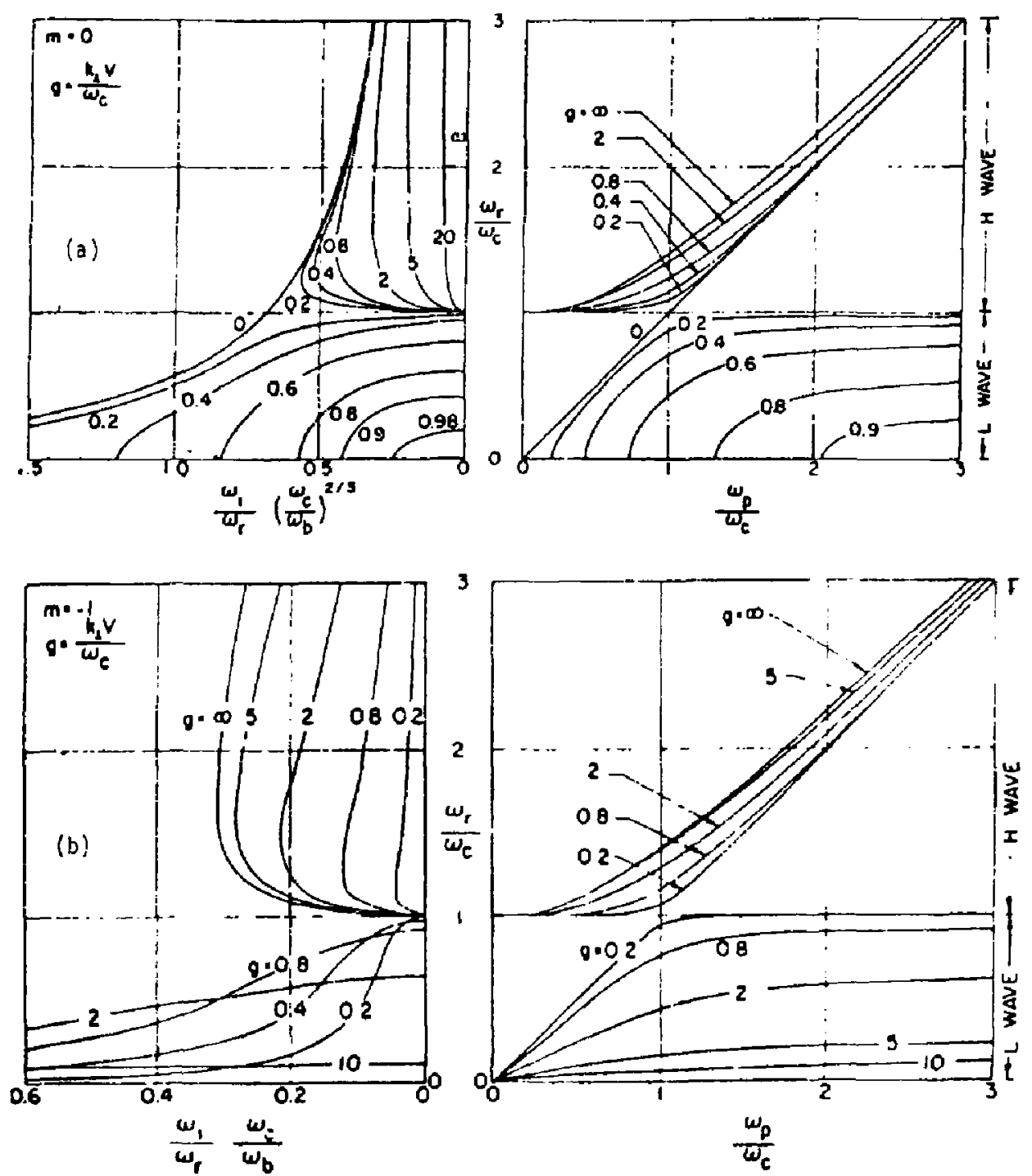

FIG. 14. Frequencies and growt: rates for cold-beam/cold-plasma instabilities (from Ref. 9): (a) dependence of the excited frequency 'w on the plasma density $\omega_{p}$ and of growth rate $\omega_{i}$ on tis for the cold-plasma/cold-parallel-beam inceraction at the $m=0$ mode, and (b) cold-plasma/cold-parallel-beam interaction at the m $=1$ mode. 

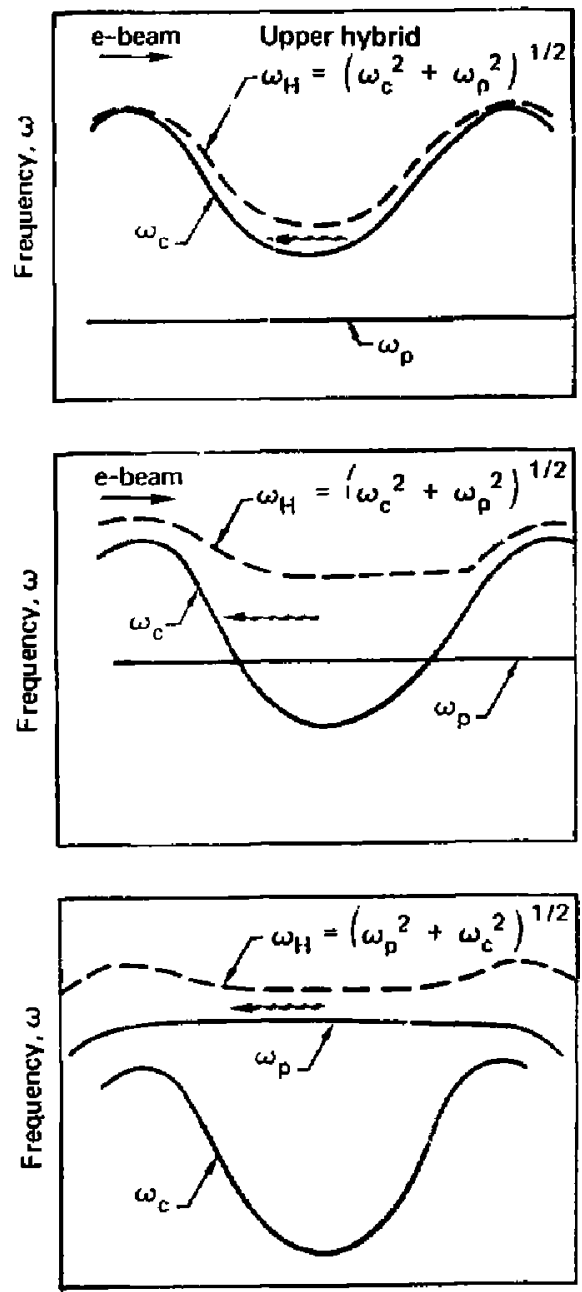

Axial distance, $z$ (a)

Low density, $\omega_{p}^{2}<<\omega_{c}^{2}$ :

Waves are generated in the frequency range $\omega_{c}: \omega<\left(\omega_{c}^{2}+\omega_{p}^{2}\right)^{1 / 2}$. The waves are absorbed through the cyclotron resonance at the mirror slope. Heating is effective.

(b)

Intermediate densities, $\omega_{p}=\omega_{c}$ :

Waves are generated in the frequency range $\omega_{p}<\omega<\left(\omega_{c}^{2}+\omega_{p}^{2}\right)^{1,2}$. The waves are absorbed through the cyclotron resonance at the mirror stope. Heating is very effective since density is high.

(c)

High densities, $\omega_{p}^{2}>>\omega_{c}^{2}$ :

Waves are again generated in the frequ $3 n c y$ range $\omega_{p}<\omega<\left(\omega_{\mathrm{s}}^{2}+\omega_{p}^{2}\right)^{1 / 2}$. However, since the frequency $\omega$ exceeds the electron cyclotron frequency at the mirror, the wave is not absorbed within the mirror. There is only harmonic heating.

FIG. 15. Plots of axial variation in the relevant frequencies with in the plasma $\omega_{c}$, $\omega_{p}$, and $\omega_{H}=\left(\omega_{p}^{2}+\omega_{p}^{2}\right)^{1 / 2}$. The figures illugtrale the resonances and cutoffs encountered in plasmas having flat density profiles. The arrows $(\sim)$ indicate the frequency and propagation direction of the generated waves. 


$$
\begin{aligned}
& \omega_{c}^{2}+\left.\omega_{p}^{2}\right|_{\min B}<\left.\omega_{c}^{2}\right|_{\max }, \lim g \rightarrow \infty \\
& \left.\max \left(\omega_{p}^{2}, \omega_{c}^{2}\right)\right|_{\text {mi n } B}<\left.\omega_{c}^{2}\right|_{\max B}, 1 \text { m } g \rightarrow 0,
\end{aligned}
$$

if the density profile is flat. For high plasma densities, the frequencies that are generated are too great to be absorbed by resonant electron cyclotron absorption of the fundamental mode. This situation is shown in Fig. 15(c). The waves therefore aither propagate out of the mirror, or tiey are absorbed by the less efficient harmonic resonances.

Electron-beam experiments other than those conducted at LLNL have consisted of either injecting the beam into a neutral gas (and hence forming a beam-generated plasma) or injecting into a mirror-trapped plasma created by, for example; a streaming-plasma jun. These plasmas would be expected to have relatively flat density profiles along the magnetic field, and would therefore exhibit a behavior consistent with the discussion above. An overview of previous experimental results supports this interpretation. From the sumary of Table I of Ref. 7 , it can be seen that if hot electrons are measured, the liaiting condition above is satisfied.

Injection of e-beams into a plasma that is driven by neutral-beam injection can produce results differing from those jugt dnscribed. Because of anisotropic $i$ an energy distribution and limited injection area, the scale length of the density variations $L_{n}=n /(d n / d z)$ may be a great deal less than the corresponding scale lengths for the magnetic field variation $I_{B}=B /(d B / d z)$. The large density variations can be the cause of several effects that are not found in experiments that have uniform densicy distributions. Thus:

- A mixture of absorption mechanisms may be at work, with absorption at the plasma frequency in one part of the plasma and absorption at the electron cyclotron resonances in other parts;

- The gradients in the density and/or the magnetic field may be too great to allow wave growth; or,

- Wave growth ray be inhibited by nonlinear processes.

The variety of situations that may occur will be considered next. 
The Frequency plots far intermediate density; $w_{\mathrm{p}} \approx_{\mathrm{c}}$ at $\mathrm{B}_{\mathrm{min}}$, and a peaked plasma profile, $L_{n}<L_{B}$, are shown in Fig. 16(a). As noted above, the wave wili propagate against the beam direction. The waves generated on the side of the plasma where the beam is injected [denoted by (1)], or wayes with $\omega>\omega_{p}$, will propagate to the left and mett the electron cyclotron resonance. It is important to note that for peaked density distributions, the resonance occurs in a region of relatively low density; the efficiency with which the wave energy is coupled to the electrons can be low, since it is a function cf the density and the scale length of the magnetic field. A large fraction of the power can propagate out of the plasma. The waves that are generated on the right side of the plasma, with $\omega<\omega_{p}$ [denoted by (2) in the sketch], will propagace toward the plasma; whether they are absorbed by the plastua or not depends upon the exciced frequency $w$ relative to the peak plasma frequency (1) por $(y / \omega)$; 1 , the waves are aisorbed at the plasma resonance; for $w / \omega)>1$, the waves pass through the plasma, are atteruated at the electron cyclotron resonance, and leave the plasma. It is seen that ef icient absorption of energy at the electron cyclotron resonance is strongly limited by spatial variation, in the plasms profile, and one would not expect the efficient generation of hot electrons and $x$ rays that is a signature of electron cyclotron resonant absorption. As was seen in the discussions of the results of the experiments conducted on the beam-driven LISL plasma-confinement devices, high-erergy $x$ rays were not found.

An interesting condition occurs for $\omega_{p}^{2} \gg \omega_{c}^{2}$ at $B_{m i n}$, and a peaked prasma density profile, as indicated in Fig, 16(b). In this case, the waves generated on the side of the plasma where the e-beam was injected wi il encounter the upper hybrid cutoff before they are able to leave the machine or be absorbed at the electrton cyclotron resonance. In the cold-plasma, infinitemedium approximation, these waves would reflect and then be absorbed in the plasma by plasma resonance. The leftward traveling waves from the right side of the plasma would be absorbed in the plasma. Waves that are generated within the pealced plasma are thesefore trapped by the upper hybrid cutoff. Inasiuch ag this trapping is effective, and the wave generation is not 1 imited by the amplitude of the waves in the plasma, the plasma electrons would be heated by this mechanism.

Wave generation within an inhomogeneous plasma is limited by gradients in the magnetic field and in the plasma density. The spatial growth rate is given 


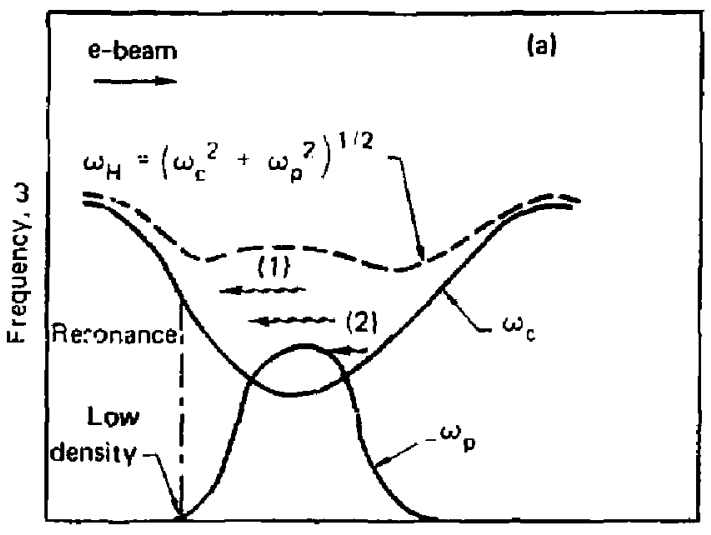

Intermediate and low densities:

For $\omega_{p} \approx \omega_{c}$ at $B_{\min }$, waves with $\omega>\omega_{p}$, max (1) will be attenuated at the $\omega_{c}$ resonance in a low-density region. Waves of type (2), $\omega<\omega_{p \text {, max }}$ gen erated on the right side of the plasma, will be absorbed at the plasma resonance. Heating efficiency depends on plasma profile and density.

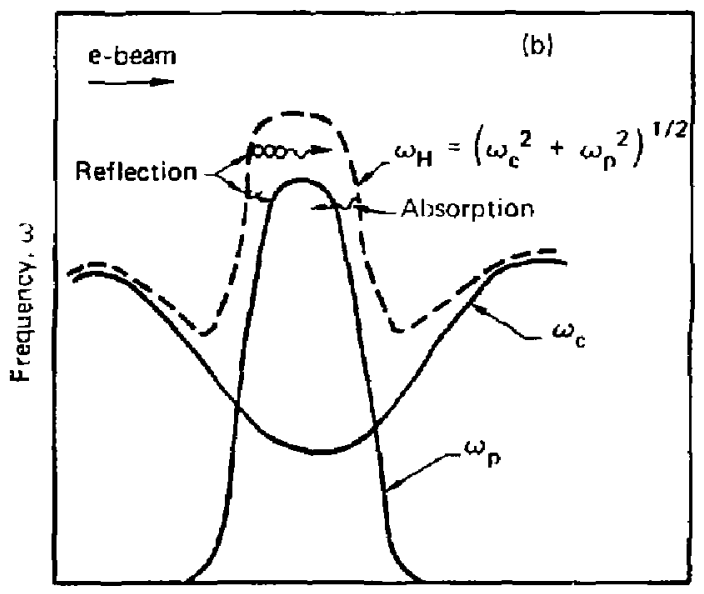

High densities:

High frequencies generated near the plasma midplane may be trapped by reflection on the upper hybrid envelope. Efficient heating has not been observed in experiments for this configuration.

Axial distance, 2

FIG. 16. Plot of axial variation in the relevanc frequencies within the plasma $w_{c}, w_{p}$, and $\omega_{1}=\left(4 t_{t}^{2}+w z_{p}^{2} 1 / 2\right.$, The figures illustrate the resonances and cutoff: encountered in plasmas having peaked density profiles. The arrows $(\sim)$ indicate the Ereugency and propagation direction of the generated waves. 
br $k_{i}$, with a corresponding length $L_{1}=1 / k_{i}$; the scale length $c_{i}$ tre inhomogeneity, i.e., the distance over which the wave number changes, is given by $\mathrm{L}_{2}=\mathrm{k} /(\mathrm{dk} / \mathrm{dz})$. Tn order that wave growth not be inhibited by the inhonogencily in the plasma and the magnetic field, the scale length of the inlomogeneity must be grearer than the scale length for wave growth, or

$$
\frac{k}{(d k / d z)} \geq \frac{1}{k_{i}} \text { for growth }
$$

If this condition is not satisfied, the synchronism conclition is not satisfied for the tire required for wave growth. An experimental verificatitn of this relation has been obtained by injecting ar e-beam into a density gradient and observing the wave growth. 12

The spatial growth rate is computed from the temporal growth rate by the re lation ${ }^{4}$

$$
\frac{k_{i}}{k_{z}}=\frac{i}{r}\left|\frac{v_{p h}}{v_{g T}}\right|,
$$

where $\mathrm{V}_{\mathrm{ph}} / \mathrm{V}_{\mathrm{gr}}$ is the ratio of the phase velocity to the group velocity. The

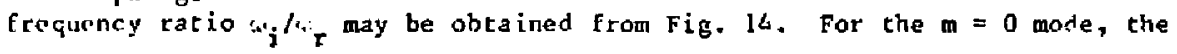
axial wave numbers for the $2 X I I B$ and the TIX experiments typically vary from 2 to $10 \mathrm{~cm}^{-1}$. The temporal growth rate ${ }^{{ }^{i}:}{ }_{i} /{ }^{\prime 2}{ }_{r}$ is on the order of $10^{-2}$ from Figs. $14(a)$ and (b). The spatial scale length for growth, $L=1 / k_{i}$, is thercfore 1 to $5 \mathrm{~cm}$.

The scale length of the plasma ishomogencities is

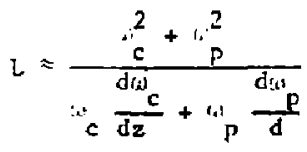

We find that the scale length due to the variation of the magnetic field alone is sufficiently large that wave growth sill not be inhibited in the LLML mirror machines. The spatial density scale length is on the order of $20 \mathrm{~cm}$ in both IMIX and 2XIIB. It is possible, therefore, that wave growth in the beam-driven 
mirror machines would be impeded by the presence of axial density gradients, especially it the actuat beam density were less than the one used ia the present estimate $\left(10^{10} \mathrm{Cm}^{-3}\right)$.

\section{SUMMARY OF MIT, 2 KIIB, AND T:IX ELECTM TN-BEAM INJECTION EXPERTMENTS}

The e-heam injection experiments on TMX showed that injection of the e-beam was not effective in decreasing the turbulence level of the confined plasma. This result is at variance with the results of the MIT and previous LLND, 'xperiments. In addition, hard $x$ rays were not observed $i n$ the $T M X$ experiments, whercas thry had heon observed in the MIT experiment. In general, what should be ubscrved en tise basis of previvus experiments, namely, bulk electron heating and the appearance of hard $x$ rays due to a populacion of energetic ( $10 \mathrm{E}_{\mathrm{hcam}}$ ') electrons, was not observed in either the $2 \times 113$ or the TAX experimenta. Tis exception cancisted of isolated instances of bulk heating. It is a hypothesis ${ }^{2}$ that the interaction of sergetic electrons has a stabilizing rffect upoil the drirt-wave instabilitims of mirror-contined plasmas. Hence, the fact that hard $x$ rays were not observed is fundamental and will be discussed first.

The basic difference between the jeam-driven 2XIIB and TNX plasmas and the plasmas that are self-generatad by e-icame or injected from stroaming-plisma guns is the large axial variation in density in the plasma from mirror to mirror. The localized density within the mirror results from the injection pattern of the neutral bcams and the highly anisotropic velncity distribution. the hat electrons appear to be due to absorption of thr generated wave powar at in electron cyclotron resonance within the mirtor. Hener, if the waves are not absorbed within the mirror, or if the absorptian process is rot effective, the hot electrons will not appear. In accordance with the discussion of Sec. 4, the relevant frenuencies within the nirror can be plotted for the TNX configation. The generated irequencies and the regions of absorption can then be found. The results for a plug density $n=1 \times 10^{13} \mathrm{~cm}^{-3}$ are shown in Fig. 17. The electron cyclotron resonance occ.urs at a density in the range 1 to $4 \times 10^{12} \mathrm{~cm}^{-3}$. If hot electrons. were present, their density was below $\sim 10^{11} \mathrm{~cm}^{-3}$, the estimated limit of dececting hard ( $\left.>50 \mathrm{kev}\right) \times$ rays. If the e-beams are injected into the plug plasma irmediately after the streaming-plasma guns have been turned off, the absorption of the excited waves 

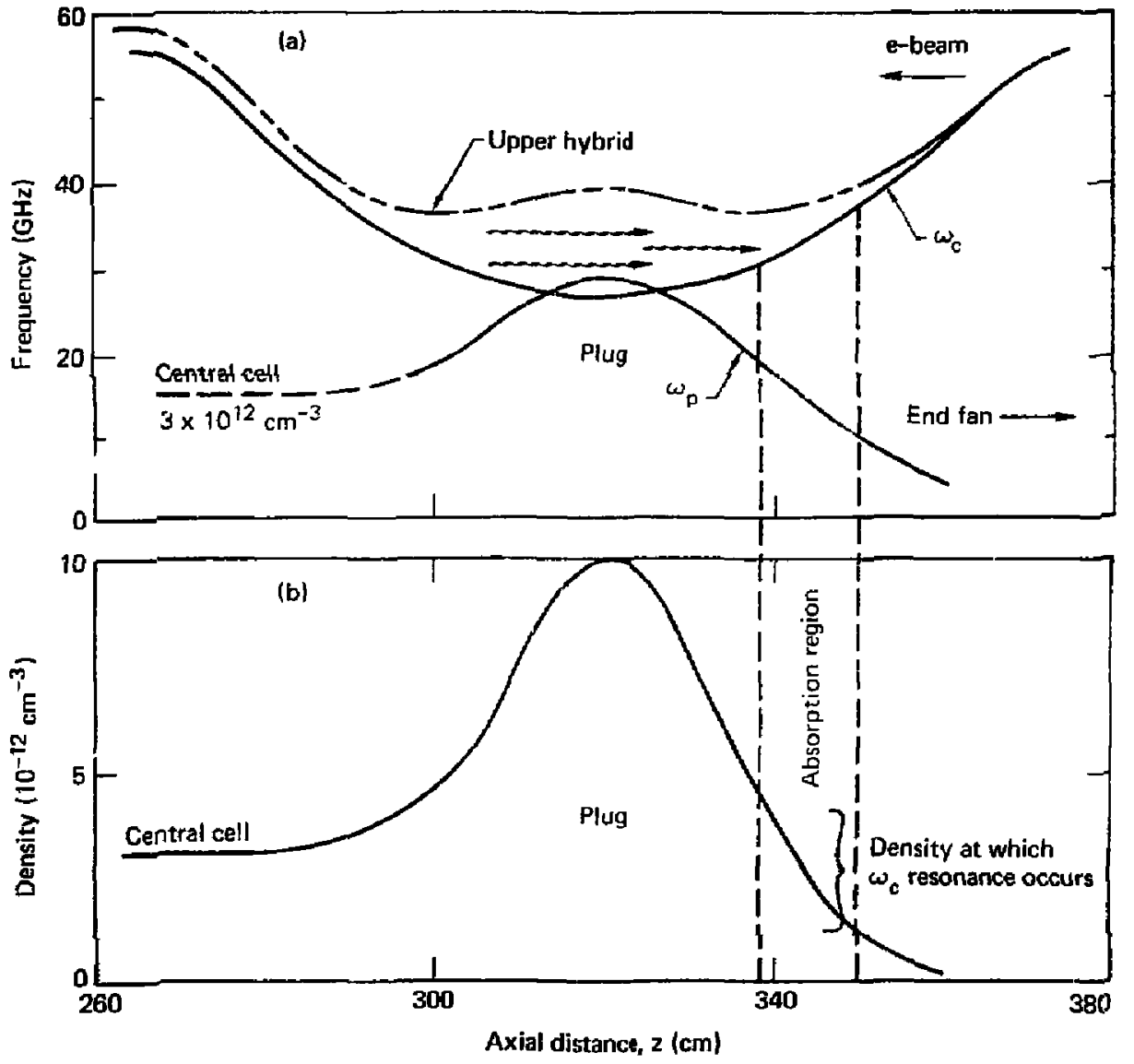

FIG. 17. The frequency plot (a) indicates the axial position of the fundamental electron cyclotron resonance. The corresponding density of the absorption region is indicated in ( $\mathrm{b}$ ). 
would be expected to be more efficient; in this case, the axial density profile would be flatter, and absorption would take place at a higher density. An example is shown in Fig. 18. In this case, since the density is assumed uniform throughout the confinement region, the absorption occurs at a density $\pi \approx 10^{13} \mathrm{~cm}^{-3}$. This may explain, in whole or in part, the observation that injection into a fully developed tandem configuration did not produce significant heating, wheress injection into a single plug immediately after the streaming-plasma gun had been turned off did produce heating. Other effects may be significanc in this comparison, for example, energy transfer to the central cell in the tandem configuration, inhibiting effect on growth due to the axial gradients, and so on.

If an e-beam is injected into a high-density plasma having a highly peaked axial disti-ihrtion, as shown in Fig. 19, the mechanism for the absorption of the excited waves is different from that described above. The waves that are generated are trapped within the upper hybrid cut-off and absorbed by the plasma resonance, if at all. This type of process will not produce hot electrons and $x$ rays. The effectiveness of the trapping and absorption mecharism is not well understood at present. Though effective heating seems possible in principle, the field gradients in the absorption region are in the direction of the magnetic field $\left(k_{1} / k_{z} \ll 1\right) ;$ it is possible, therefore, that electrons that gain energy will leave the plasma unless prevented from doing so by the ambipolar potential and scattering. The configuration shown in Fig. 19 would occur in TMX for densities in excess of $2 \times 10^{13} \mathrm{~cm}^{-3}$ in the end plugs.

\section{DISCUSS ION OF THE MIT EXPERIMENT}

A schematic of the MIT experiment is shown in Fig. 20; the magnetic field configuration consists of a guide field and a mirror trap. A streaming-plasma gun injeccs plasma along the guide field, and an e-beam is injected into the magnetic mirror along the axial field lines. The density of plasma produced and its stability properties depend on the duration of the plasma injection as we 11 as on the current of the injected e-beam. If the duration of the streaming-plasma injection exceeds $0.5 \mathrm{~ms}$, the subsequent decay in density of the plasma is stable; if the duration of injection is less than 0.5 ms, the decaying plasma is turbulent with a fundamental frequency equal to the ion cyclotron frequency corresponding to the field in the magnetic well. If the 


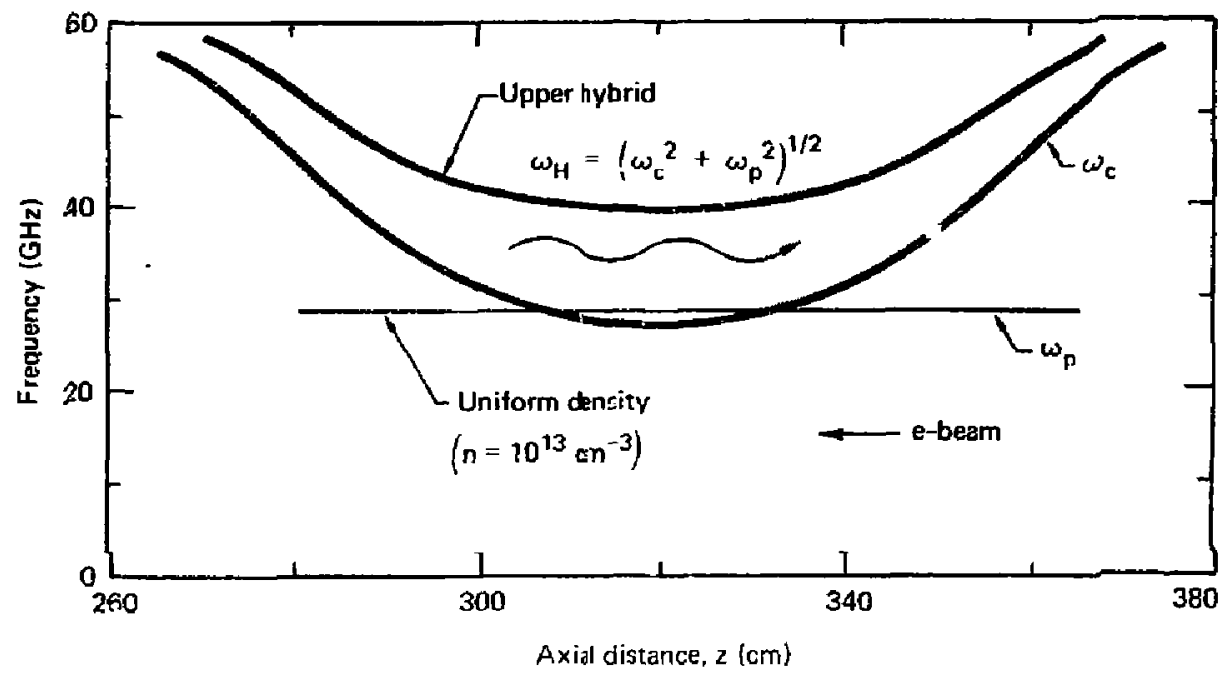

FIG. 18. The frequency plot af a plasma having a flac axial density profile show: that the fundamental electron cyclatron resonance is located in al region having a density of $10^{13} \mathrm{~cm}^{-3}$.

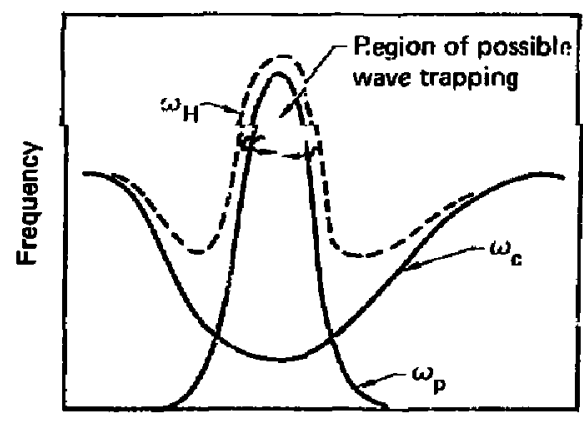

Axial distance

F. 19. Frequency plot of plasma having a highly peaked axial density distribution. The waves that are generated may be trapped within the upper hybrid cutoff and absorbed by the plasma resonance. 

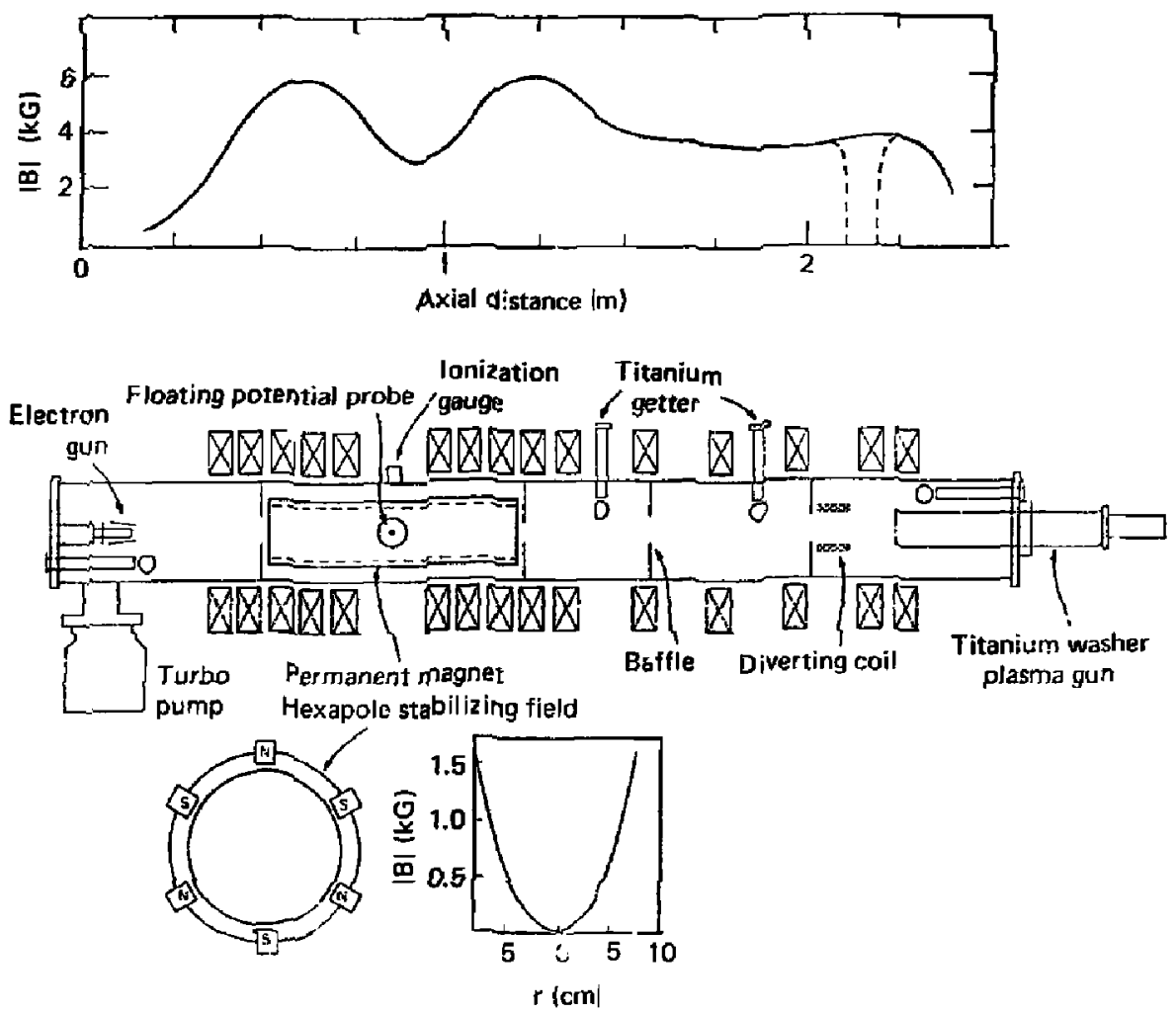

FIG. 20. A schematic of the MIT e-beam plasma stabilization experiment. 
e-beam is injected simutaneously with the streaming plasma for a duration oi 0.4 ms, $x$ rays are produced, the plasma diamagnetism increases, and the subsequent decay of plasma is stable. The maximum plasma density was greater than $2 \times 10^{13} \mathrm{~cm}^{-3}$. It is observed ${ }^{5}$ that strong heating of the electrons occurs (from $\mathrm{T}_{\mathrm{e}} \approx 10 \mathrm{eV}$ to $\mathrm{T}_{\mathrm{e}} \approx 20 \mathrm{eV}$ ) and that stabilization does not, if an electron beam is injected into a plasma having a density less than $5 \times 10^{12} \mathrm{~cm}^{-3}$.

According to the theary of Sec. 4, the range of densities for which hot electrons and $x$ rays will be generated is limited by the maximum frequency of the electron cyclotron resonance in the mirror. The magnetic field at the mirrar point is $6 \mathrm{kG}$, corresponding to a frequency of $17 \mathrm{GHz}$. Since we know that the frequencies excited by the beam/plasma instability lie between the plasma frequency and the upper hybrid frequency near the miaplane of the mirror, we also know that the maximum density for production for good coupling of beam energy to the plasma is $n \approx 3 \times 10^{12} \mathrm{~cm}^{-3}$. This density is substantially less than the maximum density, which exceeds $2 \times 10^{13}$, and efficient deposition of energy would be expected only at the beginning of the pulse when the density is low. This is confirmed by Fig. 21 from Ref. 2, which shows the $x$-ray signal $r$ ise sharply in $\sim 100 \mu \mathrm{s}$ at the beginning of the streaming-plasma pulse, and then subside as the density of the plasma continues to increase.

The decay of the trapped plasma is unstable only for limited ranges in the operating parameters. That is:

- The plasma diameter is on the order of the ion larmor radius, thus imposing a charge-exchange-induced, high-energy cut-off on the wave diffusion;

- The boundary in perpendicular velocicy space is not well defined due to the finite transit time of the ions expelled from the plasma; and

- The connection of plasma into the guide field provides good thermal conductivity for the electrons and a consequent limit on the potential gradients in the machine.

All these effects favor stability. Low density $\left(\mathrm{n}<10^{13} \mathrm{~cm}^{-3}\right)$, experiments in TMX have shown that the plasmas often are not turbulent.

It is plausible, based upon inese considerations, that the e-beam or the associated hot electrons did not directly stabilize the THX plasma by a mechanism that is not understood, and that instead the injection of the e-beams perturbed the plasma density or the boundary conditions sufficiently that the plasma parameters were outside the limited region for which unstable decay occurred. The hypothesis that the hot electrons created a local potential 


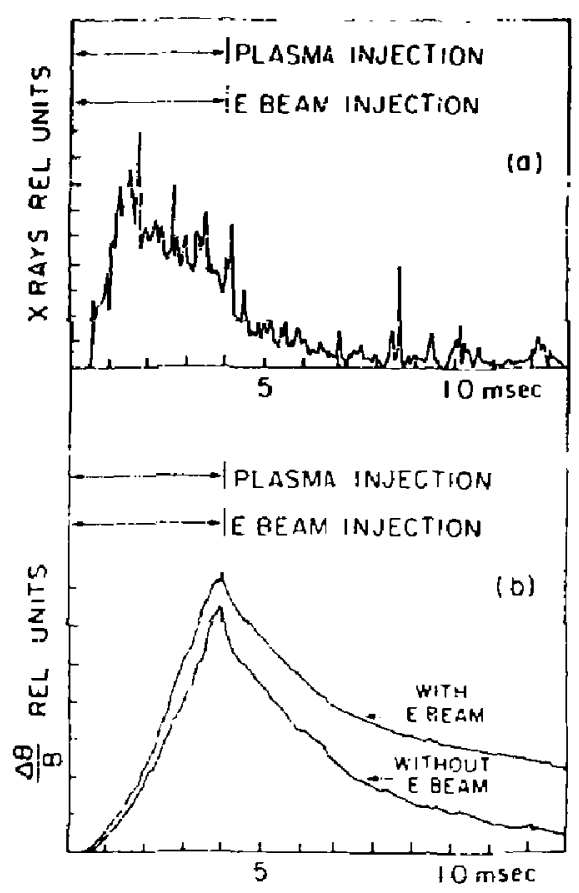

FIC. 21. Evidence of e-heam plasma interaction: (a) $x$-ray signal recorded outside the staintess-st?el vacuum chanber; (b) diamagnetis signal recorded by loop at mirror midplane. (From Ref. 2.) 
minimin, thus creating a stable configuration in the manner of the $P Q-6$ experiment, ${ }^{13}$ can be shown to be invalid due to lack of localiation of the absorbed wave power.

\section{DISCUSSION OF THE 2XITB ELECTEON-BEAM INJECTION EXPERIMENTS}

In the 2XIIB experiments conducted in June 1978, it was found that turbulence would disappear when an e-beam was injected inco a plasma that had decayed to a density $\mathrm{n} \approx 6 \times 10^{12} \mathrm{~cm}^{-3}$. Again, the plasma was not highly turbulent at this density, and experience with the TMX end plug has shown that the presence or absence of turbulence is a sengitive function of the plasma parameters at low density. Thus, injection of the e-beam could aid in maintaining the plasma and could produce a cold, stabilizing plasma. At a density of $\mathrm{n}=6 \times 10^{12} \mathrm{~cm}^{-3}$, the frequencies generated in the confinement region lie between 22 and $26 \mathrm{GHz}$ (i.e., between the plasma frequency and the upfer hybrid frequency). As a consequence, the e-beam would effectively maintain the plasma density by absorption of the excited waves at the electron cyclotron resonances located within the mitror. At higher densities, no fundamental resonance points are found within the mirror, and the waves are not absorbed. For higher plasma densities, the coupling of energy between the trapped plasma and the e-beam would not be effective, and the beam would not significantly ferturb the plasina. In sgreement wich theory, it was found experimentally tnat injection at higher densities produced no measurable effecr on the plasma parameters or its t'irbulence level.

In a second' set of experimente on $2 K I I B$, four e-deams were irjected inta the mirror-confined plasma after the streaming-plasma guns were turned off. The e-gun was located $75 \mathrm{~cm}$ outside the mirror poin: i, three e-beams were in one end fan, and one e-gun, together wi'h two streaming-dlasma gurs, were in the other end fan. It is noteworthy that injection of four e-beams instead of onm did not alter the resulcs obtained with one e-gun; the frequencies generatd by the e-beam/plasma instahility exceeded the electron cyclotron frequency with in the magnetic mirror for plasma dengities exceeding $\sim 10^{13} \mathrm{~cm}^{-3}$.

In the last set of e-beam experiments on $2 X I I B$, two e-guns on the machine centerlits were moved so that the e-beams were injected at the mirror points. In these experiments, firing the o-beams immediately after the streaming-plasma gung turned off, i.e.. at a plaswa density of 3 to $4 \times 10^{13}$, the beams 
appeared to maintain the plasma density. If the e-beams were not fired, ite plasma would decay zapidly with a time constant less than $0.5 \mathrm{~ms}$. The exponentiating time for decay of the plasma line density for a corresponding shot in which the e-beams were fired was in excess of $0.7 \mathrm{~ms}$. The turbulence level of the plasma was significantl, increased during and after the e-beam pulse, in comparison to shots in which the e-beam was not fired.

Though it is possible that the injection of e-beams has a stabilizing effact on a plasma by mechanisms that are not presently recognized, a plausible explanation for the observed effects can be found. Within the presently known instability thecry, the lessening of the curbulence level and the decay rate $c$ an be due either to a lowering of the electron temperature or to an increased population of particles having velocities less than or near to the phase velocity of the drift wave. The e-gun at one mirtor point of the machine was directly in the path of the beam from the corresponding e-gun located at the other mirror point. The generation of gas and impurities occasioned by the deposition of beam energy on the material surface of the opposing e-gun could cause a significant drainage of electron energy through inelastic collisions and conduction. The electron temperature wauld therefore decrease, with a consequent decrease in the turbulence level. A decrease of the average temperzire from $68 \mathrm{eV}$ to $59 \mathrm{eV}$ over several shots was in fact observed. It is a significant observation that the turbulence level does not increase to the level that would exist without the e-peams once these are turned off, that is, the same density does not correspond to the same turbulence level for the txo cases. This is an indication that one or more of the plasta parameters has changed, and that it is not the beat electrons that directly cause the stabilization.

CONCLUUS ION

It has been found that axial density gradients in taitror-confined plasmas can signiticantly affect the instability growth rate, the range of frequencies generated, and the mechanism and the efficiency with which the waves are absorbed within the plasma. The absorption mechanism that produces high-energy electrons and hard $x$ rays appears to be absorption at the fundamental electron cyelotron resonance within the confinement region. In plasmas having uniform axial density profiles, this mechanism prevails unless the frequencies 
generated are high enough that no fundamental resonance can be found with in the mirror. In plasmas having a highly localized density profile, as in the case of the LIW. nrutral-bean-sustained plasmas, electron cyclotron resonance absorption is dominant only for $w_{p} \lesssim w_{c}$ at $B_{\min }$ if the scale length of the density gradient is much less than that of the confining magnetic fietd, the efficiency of the absorption is lessened due to the resonance being located in a relatively low-density region. For densities such that $w_{p}^{2} \gg w_{c}^{2}$ at the center of the plasma, the dominant absorption is at the plasma resonance; this process does not yield high-energy electrons by resonant acceleration since the electric field is directed nearly along the magnetic field lines $\left(k_{1} / k_{z} \ll 1\right)$. It appears possible that these electrons, having gained energy parallel to the magnetic field, are quickly lost from the machine. The electrons, in order to escape from the machine in a transit time, must gain energy on the order of the ambipolar potential and have a tean free path greater than the machine lergth. Both conditions can be satisfied in the LLML experiments.

These observations, therefore, appear to explain both the lack of hard $x$ rays that would be associated with the mirror-confined, energetic ( $\sim 10 E_{\text {beam }}$ ) electrons and the absence of bulk heating over a large range of machine parameters $\left(\omega_{p}>\omega_{c}\right.$ at $\left.B_{\min }\right)$.

It remains to be established whether it is a lack of mirrox-confined electrons which is the cause of the failure of the e-beams to stabilize the TMX plasma or whether in fact no mechanism exists. It has been shown that absorption at the electron cyclotron resonance, the mechanisu for generating hot electrons, will dominate at low plasma densities $\left(\omega_{p} \lesssim_{c}\right.$ at $\left.B_{m i n}\right)$ and small axial gradients. This situation was found during the tests on November 29, 1979, wich e-beat injection into a single plug. For these conditions, the e-beams did not stabilize the plasma, indicating that a direct mechanigm does not exist.

These e-beam injection experiments and analysis have shown, therefore, that the regimes for which the enengy from an e-beam can be coupled to a plasma is limited by peaked density profiles, that the results of previous e-beam stabilization experiments can be explained in terms of known theory, and that injection of e-beams into ThX did not stabilize a turbulent, mirtor-confined plasma. 
APPLICATION OF ELECTRON-BEAMS TO FUTURE EXPERIMENTS

It has been found that the effectiveness with wich the power from an injected e-beam is deposited in the plaswa electrons is a function of che axizl profiles of magnetic field intensity and plasma density. It is a contusion of this study that the hig-frequency electrostatic waves generated by the e-beam/plasma interaction must be absorbed at a fundamental electron cyclotron resonance located within the confinement region in order to cransfer the energy with maximum efficiency. At the same time, the density and magnetic field gradient musc be appropriate for efficient absorption; i.e., the density in the region of absorption must be comparable to the density in the remaining part of the plasma, and $k_{z} B /(d B / d z)$ must greatly exceed unity.

If these requirenents are satisfied, ar injected e-beam can heat $p^{\text {lasma }}$ electrons and may complement or replate ECRH. Operating in a complemertary manner, as an example, e-bean injection could be employed to pre-heat electrons for subsequent ECRH. Since the efficienc; of ECRH depends on electran temperature, e-beam injection would reduce the time required to reach a given electron energy level with ECRH. A choice betveen ECRH or e-beam heating depends on the details of the heating requirements and the distribution of plasta density and magnetic field. Thus, although the effects in TMX were not significant, we can not rule out the possibility of electron beams in other machines such as TMX Upgrade and the tandem configuration of the Mirror Fusion Test Facility (MFTF-B), which have lower end-plug densities and larger axial scale lengths.

\section{ACKNGLEDGMENTS}

The e-beam experiments reported lere were conducted with the help and cooperation of the technicians, enginkers, and physicists who staff the TMX experiment. 
1. T. C. Simonen, C. A. Anderson, T. A. Casper, J. F. Clauser, F. H. Coensgen, W. C. Condit, D. L. Correll, W. F. Cunwing, J. C. Devis, R. P. Drake, J. H. Foote, R. J. Fortner, A. H. Futch, R. K. Goodman, D. P. Grubb, E. B. Hooper, R. S. Hornady, A. L. Hunt, C. V. Karmendy, B. G. Logan, R. H. Munger, W. E. Nexsen, W. L. Pickles, P. Poulsen, D. R. Slaughter, B. W. Stallard, G. A. Hallock, and O. T. Strand, Plasma Confinement Experiments in the TMX Tandem Mirror, Lawrence Livermore National Laboratory, Livermore, CA, UCRL-B3515 (i9BO).

2. R. E. Klinkowstein and L. D. Smullin, Phys. Rev. Lett. 40, 771 (1978).

3. D. P. Grubb, B. G. Logan, J. F. Clauser, F. H. Coensgen, D. L. Correll, W. F. Cummins, R. P. Drake, J. H. Foote, A. H. Futch, R, R. Goodman, W. E. Nexsen, M. Siede1, T. C. Simonen, and W. C. Turner, "Electron Beam Stabilization Experiments," in Magnetic Fusion Energy Quarterly Report-July through September, 1978, M. A. karrison and J. R. strack, eds., Lawrence Livermore Laboratory, Livermore, CA (1978).

4. D. P. Grubb, "Electron-Beam Startup," in Magnetic Fusion Energy Quarter1y Report--January through March, 1979, M. A. Harrison and J. R. Strack, eds., Lawrence Livermore Laboratory, Livermore, CA (1979).

5. D. E. Baldwin and B. G. Logan, Lawrence Livermore Laboratory, Livermore, CA, Internal Document MFGiLi/l6-65 (February 17, 1978). Readers outside the Laboratn.y who desire further information on LLML internal documents should address their inquiries to the Technical Information Department, Lawrence Livermore National Laboratory, Livermore, California 94550.

6. D. D. Ryutov, Sov. Phys _-JETP 30, 131 (1970).

7. M. Seidl, A Review of Electron Beam Heating of Magnetic Mirror Confined Plasmas, with Applications to the Tandem Mirror Experiment, Lawrence Livermore Nationa I Laboratory, Livermore, CA, UCRL-52759 (1979).

8. L. D. Smullin, A Review of the Beam Plasma Discharge, Massachusetts Institute of Technology, Cambridge, MA, PFC-RR-80-7 (1980).

9. M. Seidl, Phys. Fluids 13, 966 (1970).

10. N. Seidl and P. Sunka, Nucl. Fusion I, 237 (1967).

11. V. Kopecky and J. Preinhaelter, Plasma Phys. 11, 333 (1969). 
12. L. D. Bollinger, W. Cart, H. Liu, and N. Seid1, Phys. Fluids 17, 2142 (I975).

13. M. S. Ioffe, B. I. Kanaev, V. P. Pastukotov, and E. E. Yushitanov, Sov. Phys.--JETP 40, 1064 (1975). 